\title{
Educación financiera basada en el bitcoin y la inclusión en planes de estudio
}

\author{
Bitcoin-based Financial Education and Inclusion in Curricula
}

Educação financeira baseada em Bitcoin e inclusão nos currículos

Sergio Gabriel Ordóñez Sánchez

Centro de Estudios e Investigaciones para el Desarrollo Docente CENID A.C., México

sergio.ordonez@correo.buap.mx

https://orcid.org/0000-0002-4122-4225

\section{Resumen}

El desarrollo de tecnologías ha impactado en varios sectores de la vida humana. Por supuesto, el educativo no es la excepción. Desde el año 2009 a la fecha, el concepto de criptomoneda ha causado furor a nivel mundial, específicamente la bitcoin, que utiliza tecnología blockchain, un código abierto para operar sin una autoridad central o banco. Esta investigación tuvo por objetivo determinar el rezago que existe en los planes de estudio en las áreas de educación financiera, administrativa, contable y fiscal a nivel superior respecto a este tema. Bajo un método deductivo, se encuestó a una muestra de estudiantes de la Facultad de Contaduría Pública de la Benemérita Universidad Autónoma de Puebla con la finalidad de obtener datos que determinen el interés y las necesidades de los usuarios de bitcoin. Los resultados obtenidos demuestran un área de oportunidad contundente para atender este rezago, debido a que existen operaciones realizadas con esta criptomoneda sin la pedagogía básica de su funcionamiento. Como parte de las conclusiones se insta a la reestructuración de los programas de estudio tomando en cuenta la incorporación de 


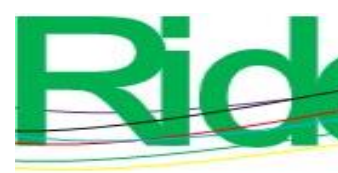

Revista Iberoamericana para la Investigación y el Desarrollo Educativo ISSN $2007-7467$

conceptos relacionados con las criptomonedas, y así cumplir con la formación de profesionistas preparados para las exigencias del mercado actual.

Palabras clave: bitcoin, educación financiera, planes de estudio.

\section{Abstract}

The development of technologies has impacted various sectors of human life. Of course, education is no exception. Since 2009 to date, the concept of cryptocurrency has been all the rage worldwide, specifically bitcoin, which uses blockchain technology, an open source code to operate without a central authority or bank. The purpose of this research was to determine the lag that exists in the curricula in the areas of financial, administrative, accounting and tax education at the higher education level with respect to this topic. Under a deductive method, a sample of students from the School of Public Accounting of the Benemérita Universidad Autónoma de Puebla were surveyed in order to obtain data to determine the interest and needs of bitcoin users. As part of the conclusions, the restructuring of study programs is urged, taking into account the incorporation of concepts related to cryptocurrencies, in order to comply with the training of professionals prepared for the demands of today's market.

Keywords: bitcoin, financial education, curricula.

\section{Resumo}

O desenvolvimento de tecnologias tem impactado diversos setores da vida humana. Claro, a educação não é exceção. De 2009 até hoje, o conceito de criptomoeda causou sensação mundial, especificamente o bitcoin, que usa a tecnologia blockchain, um código aberto para operar sem uma autoridade central ou banco. O objetivo desta pesquisa foi determinar a defasagem que existe nos planos de estudos nas áreas de educação financeira, administrativa, contábil e tributária de nível superior em relação ao tema. Sob o método dedutivo, uma amostra de alunos da Faculdade de Contabilidade Pública da Universidade Autônoma Benemérita de Puebla foi pesquisada a fim de obter dados que determinassem o interesse e as necessidades dos usuários de bitcoins. Os resultados obtidos demonstram uma área de esmagadora oportunidade de abordar esta defasagem, devido ao facto de existirem operações 


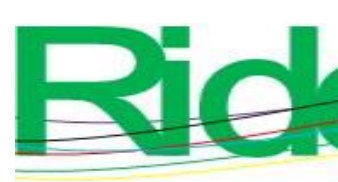

Revista Iberoamericana para la
Investigación y el Desarrollo Educativo ISSN $2007-7467$

realizadas com esta criptomoeda sem a pedagogia básica do seu funcionamento. Como parte das conclusões, preconiza-se a reestruturação dos programas de estudos tendo em conta a incorporação de conceitos relacionados com criptomoedas, e assim cumprir a formação de profissionais preparados para as exigências do mercado atual.

Palavras-chave: bitcoin, educação financeira, planos de estudo.

Fecha Recepción: Mayo 2020

Fecha Aceptación: Mayo 2021

\section{Introducción}

La historia del dinero es tan antigua como la civilización misma. En tiempos pasados, seguir el endeudamiento de alguna persona era una tarea fácil, y se hacía de manera mental: debías un trozo de carne por unas cuantas frutas. Créditos y débitos eran reconocidos en la memoria de cada persona. Básicamente, un libro de contabilidad mental. "Las monedas son un lenguaje que nos permite expresar calor transaccional entre personas, es una tecnología más antigua que la rueda, tan antigua como el fuego" (Antonopoulos, 2020). A través del tiempo, se estableció el trueque y luego las monedas como intercambio de mercancías.

Prácticamente en todas las culturas las monedas cumplen con las siguientes cinco condiciones: deben ser relativamente escasas (escaso), fácilmente identificables (reconocible), divisibles en partes más pequeñas (divisible), que una pueda ser sustituida por otra de igual valor (fungible) y que se pueda llevar a todas partes sin demasiados problemas (portable). Las personas utilizan diferentes tipos de moneda a manera de intercambio. Y en esta era han surgido las monedas digitalizadas, llamadas criptomonedas.

Ahora llevamos a cabo prácticas financieras más complejas; los agentes financieros practican titulización, siempre usan dinero de otras personas, venden deudas, usan transferencia de riesgo o cualquier otro tipo de manipulación financiera. Esto es lo que llaman innovación. Y cuando se habla de innovación financiera, la criptomoneda bitcoin, sin duda, es uno de los casos que está revolucionado la economía global.

La historia dice que la innovación más revolucionaria y perturbadora casi siempre viene de las periferias, no de lo que ya se ha establecido. Los verdaderos innovadores ven el mundo de manera diferente, su perspectiva es más grande, crean nuevos productos y sistemas enteros que producen nuevas industrias. Steve Jobs mencionó que los innovadores son capaces de encontrar "la cuadratura del círculo" (Pozzi, 2011). 


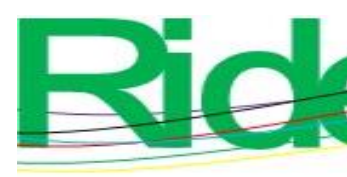

Revista Iberoamericana para la Investigación y el Desarrollo Educativo ISSN $2007-7467$

Para finales del año 2017, la criptomoneda tuvo un desarrollo exponencial: llegó a cotizar arriba de los 19000 dólares (Bit2Me Academy, 2017). Evidentemente, esto despertó el interés en el entorno económico internacional y nacional. Ahora se ha convertido en un medio de pago e inversión utilizado por las nuevas generaciones para realizar la compraventa de servicios y productos. Y es en este punto donde el ámbito educativo quedó rezagado, al no contar con la preparación de los futuros profesionistas en el campo de los negocios, por lo cual se busca contemplar estos temas basados en criptomoneda dentro de los planes de estudio a nivel superior.

Bitcoin es una moneda virtual o criptomoneda que se utiliza para comprar y vender bienes o servicios de persona a persona sin importar la nacionalidad ni la distancia en cualquier parte del mundo. Una moneda con la cual no existen intermediarios bancarios. Una moneda diseñada a base de firmas digitales, cuya seguridad está respaldada en una red de verificación dirigida por nodos. A pesar de compartir la principal característica del dinero en efectivo, que es la de realizar transacciones, se trata de una moneda virtual, es intangible. Sin duda, cada día está teniendo mayor aceptación en las diferentes economías de diversos países.

El 31 de octubre de 2008, Satoshi Nakamoto (pseudónimo de la persona o grupo de personas que creó esta criptomoneda) liberó una publicación en la lista de criptografía de metzdown.com donde describe el protocolo bitcoin. Allí menciona que el comercio en Internet ha llegado a depender casi exclusivamente de las instituciones financieras, que actúan como terceros de confianza para procesar pagos electrónicos. El objetivo de Nakamoto (2008) y del protocolo en cuestión fue prescindir de este mediador. El bitcoin se presenta como una moneda virtual utilizada por usuarios en el mundo y que, a diferencia de las monedas existentes, utiliza una versión peer-to-peer (igual a igual) que permite que los pagos en línea se envíen directamente sin tener que pasar a través de una institución financiera. Mediante firmas digitales y a través de un sistema de minería basado en la solución de algoritmos matemáticos, se soluciona el problema del doble gasto. Aquí los CPU figuran como parte principal en el procesamiento de la generación y control de nodos. El bitcoin, por tanto, no cuenta con respaldo de ningún banco mundial o nacional ni tiene emisor, como es el caso de cualquier moneda tradicional. De esta forma, el intercambio depende del valor que compra y del que vende dan a dicho valor. 


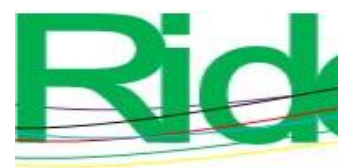

Revista Iberoamericana para la Investigación y el Desarrollo Educativo ISSN 2007 - 7467

del euro? ¿Las universidades de México contemplan dentro de sus planes de estudio el tema de criptomonedas? ¿Están preparados los futuros profesionistas para el manejo de criptomonedas en el entorno financiero? ¿Es necesario implementar en los programas de estudio de las universidades de México temáticas y plataformas para determinar cuáles son las razones para utilizar el bitcoin como una moneda y herramienta tecnológica en las transacciones de las entidades financieras mexicanas?

Es importante conocer las respuestas a cada una de estas preguntas básicas. Al momento de reconocer el rezago en estos temas se deberán identificar las áreas de oportunidad que deben cubrirse inmediatamente para poder estar a la altura y en equidad con los profesionistas de otros países y así formar individuos capaces de lidiar con los retos del presente y del futuro.

\section{Objetivos}

\section{Objetivo general}

- Conocer, analizar y evaluar el manejo de la criptomoneda bitcoin en el entorno educativo y financiero para determinar las ventajas y desventajas al utilizar este concepto como medio de pago en las transacciones de las empresas mexicanas, y de esta forma establecer una propuesta de temas a incorporarse en los programas de estudio de la Facultad de Contaduría Pública de la Benemérita Universidad Autónoma de Puebla.

\section{Objetivos específicos}

- Conocer y analizar los conceptos básicos de la criptomoneda bitcoin para determinar las ventajas y desventajas de su funcionamiento.

- $\quad$ Evaluar los factores importantes, según usuarios expertos en el tema, para establecer las áreas de oportunidad en el ámbito educativo.

- Establecer una propuesta de temas de estudio que giren en torno a la criptomoneda bitcoin para ser incluida en los programas de estudio en la Facultad de Contaduría Pública de la Benemérita Universidad Autónoma de Puebla. 


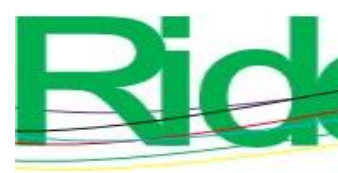

Revista Iberoamericana para la
Investigación y el Desarrollo Educativo
ISSN $2007-7467$

\section{Hipótesis}

- La incorporación a los planes de estudio de temas basados en criptomonedas fortalecerá el desarrollo profesional de los alumnos de la Facultad de Contaduría Pública de la Benemérita Universidad Autónoma de Puebla.

\section{Desarrollo}

Andreas Adriano y Hunter Monroe (2016) mencionan que lo mejor del dinero en efectivo es la simplicidad de las operaciones. Uno entrega dinero y recibe algo. Nadie le pregunta el nombre, la dirección, el número de teléfono, la fecha de nacimiento, el número de seguro social, el salario y la antigüedad en el trabajo actual...El efectivo genera confianza instantánea entre comprador y vendedor (Adriano y Monroe, 2016). Esa confianza la logrado replicar, a su manera, el bitcoin.

Palacios, Vela y Tarazona (2015) concluyen que el bitcoin es considerado una moneda experimental y que carece de reconocimiento dentro de la economía global, sin embargo, se utiliza como alternativa a los costosos sistemas tradicionales. Se trata pues de una paradoja. A pesar de que carece de reconocimiento, es utilizado en tiempo real como medio de envío, pago y de inversión en distintos países.

En Inglaterra, Alemania y China, los bancos están usando cadenas de bloques a modo de registros con la idea de simplificar las transacciones y el almacenamiento de información, atendiendo a las características de mayor velocidad, menores costos, una alta seguridad y eliminación de errores. Don Tapscott y Alex Tapscott (2017) mencionan que el bitcoin o cualquier otra moneda digital no se guarda en archivos que estén en un lugar concreto; está representado por transacciones que se registran en una cadena de bloques, que es una especie de hoja de cálculo o registro que usa los recursos de una amplia red entre iguales para verificar y aprobar todas y cada una de las transacciones.

Ramos (2014) señala que el bitcoin es objeto de fuertes críticas debido a que otorga anonimidad a cada usuario, esto es, a las entidades regulatorias y los bancos centrales les resulta complicado rastrear las transacciones entre los usuarios e imposible descifrar sus identidades reales y ubicación física, por lo que es definido como un potencial instrumento para cometer actos criminales e ilegales, por ejemplo, lavado de dinero o fraude. 


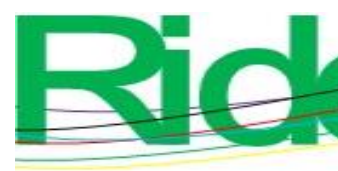

Revista Iberoamericana para la Investigación y el Desarrollo Educativo ISSN 2007-7467

Al ser un tema innovador, en México existen pocas fuentes de consulta, sin embargo, existe ya de manera legal una ley que está tratando de regular las operaciones basadas en esta criptomoneda, publicada el día 9 de marzo de 2018 y llamada Ley para Regular las Instituciones de Tecnología Financiera (Presidencia de la República, 2018).

A partir de la publicación de esta ley, surgió una nueva etapa para la utilización y la regularización de las instituciones que manejan criptomonedas. Según El Financiero de México (2018), esta ley tiene por objetivo regular los servicios financieros que prestan las instituciones de tecnología financiera, así como su organización, operación y funcionamiento, particularmente de las del sector privado. De los 145 artículos divididos en siete títulos que conforman la Ley para Regular..., este medio redactó los siguientes puntos a modo de síntesis:

- $\quad$ Surge de una iniciativa enviada el 10 de octubre de 2017, la cual fue aprobada en la Cámara Alta el 5 de diciembre de ese mismo año.

- Las instituciones de tecnología financiera se entienden como aquellas plataformas a través de las cuales se facilita la celebración de operaciones y servicios financieros relacionados con el acceso al financiamiento e inversión, servicios de emisión, administración, redención y transmisión de fondos de pago electrónico, además del uso de activos virtuales en dichas operaciones.

- Dichas instituciones, en el sector privado, son las de pagos electrónicos, de financiamiento colectivo, de activos virtuales y de asesoría financiera electrónica, entre otras.

- La nueva ley, entre otros aspectos, propone considerar el uso de activos virtuales, como las criptomonedas, previa autorización del Banco de México (Banxico).

- $\quad$ Busca prevenir y mitigar el riesgo de lavado de dinero y financiamiento al terrorismo, estableciendo un marco regulatorio aceptado y aprobado internacionalmente, con estándares mínimos de identificación del cliente, que permita prevenir este tipo de conductas.

- $\quad$ La ley en cuestión prevé un régimen de divulgación de riesgos por virtud del cual las instituciones de tecnología financiera se encuentren obligadas a difundir la información necesaria para que sus clientes identifiquen los riesgos que asumirán al momento de celebrar operaciones con o a través de ellas. 


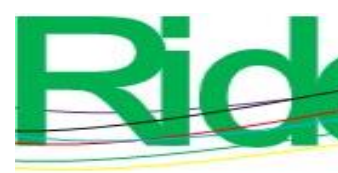

Revista Iberoamericana para la
Investigación y el Desarrollo Educativo ISSN 2007-7467

- $\quad$ Pretende establecer el gobierno corporativo de las instituciones de tecnología financiera al contar con un consejo de administración, director general y comité de auditoría con base en el número de operaciones o clientes, modelos de negocios, activos intermediados o nivel de capital neto que ostentan dichas instituciones.

- También considera un marco normativo en el que se contemplan las sanciones administrativas y penales para los casos en que se incumpla con lo establecido en la ley o disposiciones que de ella emanen (El Financiero, 2018).

Ahora bien, el portal elbitcoin.org pronostica que el número total de bitcoins tenderá a 21 millones con el tiempo. Su oferta crece en una serie geométrica (con una razón constante). A medida que la cantidad de bitcoins se aproxime al límite de 21 millones, se espera que la economía de este tipo entre en deflación.

Los bitcoins, entre tanto, son divisibles hasta ocho decimales (dándonos 2.1 x 10 elevado a la quinceava potencia - 2.1 miles de billones - de unidades totales), y potencialmente aún más, lo cual remueve las limitaciones prácticas a los ajustes de precio en un contexto deflacionario (elbitcoin.org, 2013).

El mismo sitio menciona algunas de las ventajas al utilizar la criptomoneda bitcoin:

- $\quad$ Mayor privacidad, al eliminar la interferencia de terceros en las transacciones.

- $\quad$ Aumento decreciente y predecible de la masa monetaria, lo cual ayuda a preservar (y probablemente a mejorar) el poder adquisitivo de los usuarios.

- Menores (e incluso nulos) costos de transacción en la Web, cuyos niveles actuales (por ejemplo, a través de PayPal) entorpecen el libre intercambio.

- Simplifica y acelera el pago de persona a persona, prescindiendo de intermediarios no deseados.

- $\quad$ Una dirección bitcoin puede ser anónima, si así lo desea el usuario.

- $\quad$ Permite hacer transferencias a cualquier parte, ignorando barreras geográficas y políticas.

- $\quad$ Es transparente: aunque nadie está forzado a revelar su identidad, todas las transacciones quedan grabadas en un registro de libre acceso.

- Admite transacciones complejas (depósitos en custodia; seguros de depósitos; garantías; mediación, etc.) con un firme respaldo criptográfico para todo tipo de reglas y condiciones libremente acordadas por las partes. 


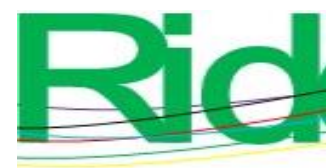

Revista Iberoamericana para la
Investigación y el Desarrollo Educativo
ISSN $2007-7467$

- $\quad$ Nunca se detiene: no hay feriados ni fines de semana para las operaciones en bitcoins.

- Hace viables los micropagos a gran escala.

- Impide la congelación y la confiscación de fondos.

- Impide la reversión involuntaria de pagos.

- Impide la restricción arbitraria de bienes y servicios que pueden adquirirse.

- $\quad$ Permite la acumulación de fortunas enormes en un espacio ínfimo.

- $\quad$ Puede ocultarse fácil y gratuitamente, sin tener que apelar a terceros para su resguardo y traslado.

- $\quad$ Puede guardarse simultáneamente en múltiples localizaciones.

- $\quad$ No requiere confianza en un tercero ni en un determinado sistema legal para preservar su valor.

- $\quad$ Facilita la protección contra el robo en todas sus formas: la tecnología en la que se basa el protocolo de bitcoin es varias veces más segura que la empleada por los bancos y las tarjetas de crédito.

- $\quad$ No puede ser eliminado por ataques legales/informáticos, dada su naturaleza descentralizada.

- $\quad$ No puede falsificarse.

- $\quad$ Es fácil e instantáneamente reconocible.

- $\quad$ Es, a los fines prácticos, infinitamente divisible.

Cada vez es mayor el número de personas que rompen el medio de realizar operaciones virtuales y gozan ya de una libre comercialización en comercio electrónico, disfrutando de una velocidad y seguridad en sus cobros y pagos.

Cada vez más comercios y sitios electrónicos comerciales le abren las puertas al bitcoin. Incluso se han difundido algunos casos de personas e incluso grupos de personas que sobreviven en la economía actual solo con el uso de esta moneda (Jiménez, 2020).

En México, algunos pequeños empresarios ya tienen claro hacia dónde va el futuro de los pagos al aceptar las criptomonedas en sus locales (Huffpost México, 2017). Empresas como Mobla (fabricante de muebles) apostaron por el manejo de bitcoin, sin embargo, solo han recibido un pago en esta criptodivisa, y mencionan que el mercado en México no está 


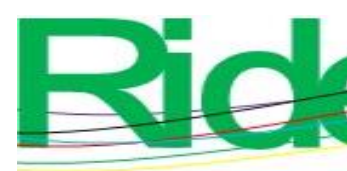
Revista Iberoamericana para la
Investigación y el Desarrollo Educativo
ISSN $2007-7467$

preparado y se necesita de más información por parte de los consumidores (Huffpost México, 2017).

David Noriega, propietario de la tienda de Fantástico Cómics, considera que el bitcoin va a revolucionar la manera de realizar pagos de una manera similar a como el Internet tuvo su impacto en la sociedad. Su confianza en la criptomoneda le llevó a instalar un cajero de bitcoins en el año de 2014. Sin embargo, señala que la gente aún no usa los bitcoins para sus compras, ya que se utiliza principalmente como una forma de ahorro o de inversión especulativa (Huffpost México, 2017).

Por supuesto, México es capaz de manejar una moneda como el bitcoin, sobre todo teniendo en cuenta que la aceptación de este país en el mercado global en los últimos años se ha incrementado gracias al mercado electrónico. Sitios como Mercadolibre y Amazon de México han sido ventanas para realizar múltiples transacciones con diversos países y regiones del mundo. La confianza del comprador se refleja en el número de transacciones diarias realizadas, mayoritariamente por un sector mayoritario perteneciente a las clases sociales media y media alta. Actualmente, con una computadora y conexión a internet, es posible comprar una tableta en China y recibir el producto en cuestión de días.

En el terreno de la educación, el manejo de bitcoin se ha convertido en uno de los temas principales, sobre todo en carreras administrativas y financieras. El tema de criptomonedas se vio reforzado una vez que países como México regularon el uso, caso contrario a Rusia y algunos países de Asia, donde realizar transacciones con bitcoin está prohibido.

En España, la Universidad Alicante imparte desde 2015 el curso en línea abierto y masivo (MOOC) “Bitcoin, la moneda virtual”, que responde a las preguntas más comunes sobre el tema (Fernández, 2017). Y a través de Coursera, se imparte el curso "Tecnología bitcoin y criptomoneda", respaldado por Princeton, y cuyo éxito produjo que se adaptara a un libro de registro académico. De igual forma, la Universidad de Nueva York y la Universidad de Stanford focalizan sus programas al estudio de las criptomonedas (Fernández, 2017).

Mientras que, en la faceta informal de la educación, destacan grupos en comunidades virtuales (Facebook, Meetup, blogs y wikis) que ofrecen información al respecto. Sin embargo, precisamente por su naturaleza informal, no suelen contar con un temario 


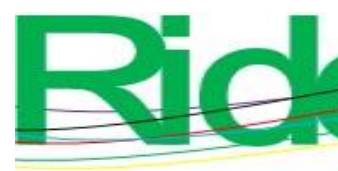

Revista Iberoamericana para la
Investigación y el Desarrollo Educativo ISSN 2007-7467

estructurado y muchas de las veces los integrantes se enfocan más en captar a nuevos usuarios de criptomonedas y dirigirlos a determinados sitios para llevarse una comisión.

Sumado a estos espacios virtuales, podemos encontrar un sin número de aplicaciones relacionadas con bitcoin: desde carteras electrónicas hasta herramientas de seguimiento en tiempo real de las cotizaciones de diferentes criptomonedas.

Un sinfín de conferencias y trabajos de investigación son colocados en Internet para consulta y sobre todo para entender el funcionamiento y lenguaje de las criptomonedas. Teniendo en cuenta lo hasta aquí mencionado, resulta indispensable, y hacerlo de manera urgente, un programa de estudio que se enfoque exclusivamente en definiciones y conceptos del uso de las criptomonedas, así como en la regulación de estas como medio de pago e inversión.

\section{Metodología, técnicas y materiales empleados}

La investigación se realizó bajo un método deductivo. De lo general a lo particular, analizaron los conceptos de los temas.

Es una investigación exploratoria debido a que se adoptó un enfoque cualitativo, con un énfasis en el análisis de fuentes secundarias (libros, periódicos, revistas, y páginas electrónicas).

Los métodos de estudio se llevaron a cabo por medio de un instrumento tipo encuesta. Para el estudio, se consideró una muestra de 500 estudiantes de un grupo de 3500 estudiantes de la Facultad de Contaduría Pública de la Benemérita Universidad Autónoma de Puebla; alumnos que mostraron interés en el tema de criptomonedas y en el caso particular de bitcoin durante el periodo primavera 2019.

Para la construcción del instrumento, se consideró el uso y funcionamiento de las criptomonedas, como medio de pago y medio de inversión, con el objeto de recopilar los datos necesarios para elaborar un plan de estudio actualizado especializado en educación financiera.

Al ser un tema especializado, se omitieron los resultados de personas que no son afines al tema, y así se analizaron solo los datos de usuarios con experiencia en el área. Después de aplicado el instrumento, se discutieron los resultados obtenidos. 


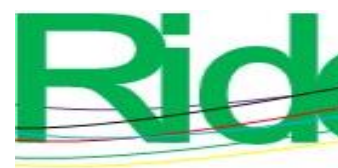

Revista Iberoamericana para la
Investigación y el Desarrollo Educativo ISSN $2007-7467$

\section{Participantes}

En la Facultad de Contaduría Pública de la Benemérita Universidad Autónoma de Puebla se ofertan tres licenciaturas: licenciatura en Contaduría Pública, licenciatura en Dirección Financiera y la licenciatura en Administración y Dirección de Pequeñas y Medianas Empresas. De las tres licenciaturas, se seleccionaron alumnos de sexto semestre en adelante. El cuestionario se aplicó de forma presencial y a distancia. Cabe mencionar que la primera pregunta del cuestionario se refiere al conocimiento de criptomonedas: a quienes respondieron de forma negativa a dicho cuestionamiento se les descartó de inmediato.

Se aplicaron adicionalmente 20 cuestionarios de forma aleatoria a docentes de la facultad a efectos de comparar el conocimiento de criptomonedas y el contexto de operación y funcionamiento del bitcoin.

\section{Instrumentos}

El instrumento de recogida de datos corresponde a un cuestionario de 20 preguntas cerradas. Este cuestionario fue estandarizado de tal forma que se aplicó exclusivamente a alumnos de sexto semestre en adelante con experiencia en el manejo de criptomonedas.

Como prueba piloto, se iniciaron los cuestionamientos y entrevistas a expertos en el tema, resultado de un foro abierto entre estudiantes y docentes, donde el argumento principal fue la aceptación de la Ley Fintech, así como la regulación de criptomonedas en México. Posteriormente, se perfeccionó el cuestionario para la aplicación a la muestra.

\section{Procedimientos}

Se analizó el marco teórico para conocer el origen y funcionamiento de la criptomoneda bitcoin como medio de pago y como instrumento de inversión en México. Para obtener una conclusión y diseñar una propuesta óptima, se utilizaron encuestas y entrevistas. A continuación, algunos detalles de cada de una de las etapas e instrumentos:

- Análisis de documentos: se consultaron diferentes fuentes de información electrónicas para establecer conceptos y definiciones previas a las entrevistas y encuestas.

- $\quad$ Entrevistas y criterios de especialistas: se realizaron entrevistas a docentes del área de contabilidad y finanzas con experiencia en el manejo de criptomonedas con el objetivo de recolectar diferentes perspectivas y conocer sus posiciones acerca del bitcoin y 


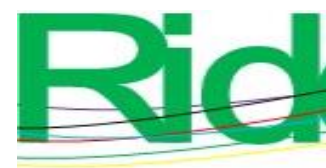

Revista Iberoamericana para la
Investigación y el Desarrollo Educativo
ISSN $2007-7467$

la viabilidad de incluir en los planes de estudio de las licenciaturas temas relacionados con las criptomonedas.

- $\quad$ Encuestas: destinadas a una muestra de 500 estudiantes de nivel licenciatura, quienes han tenido algún acercamiento a temas de criptomoneda y en especial al bitcoin, con el objetivo de conocer el interés académico sobre el tema y su nivel de conocimiento sobre el mismo.

En función de los tres instrumentos, se pretende concluir con las ventajas y desventajas de utilizar la criptomoneda bitcoin, así como la implementación de estos temas en los planes de estudio de las licenciaturas ofertadas en la Facultad de Contaduría Pública de la Benemérita Universidad Autónoma de Puebla.

- $\quad$ Estrategia de análisis de datos: se analizaron los datos obtenidos, codificando las respuestas a las preguntas cerradas con valor de uno como respuesta afirmativa y con valor de cero para una respuesta negativa.

También a partir de la siguiente escala: $5=$ Totalmente de acuerdo, $4=$ De acuerdo, 3 = Imparcial, 2 = No muy de acuerdo y $0=$ Totalmente desacuerdo.

Se elaboran gráficas tipo pastel para mostrar los resultados en porcentajes. Cabe aclarar, por último, que se eliminaron los extremos de la muestra con valores máximos y mínimos para reducir el grado de error y sesgo.

\section{Resultados}

A continuación, se analizan las encuestas realizadas a la muestra de estudiantes previamente seleccionada, correspondiente a alumnos de licenciatura de sexto semestre en adelante de la Facultad de Contaduría Pública de la Benemérita Universidad Autónoma de Puebla, que fue aplicada de manera directa y vía correo a los interesados. 


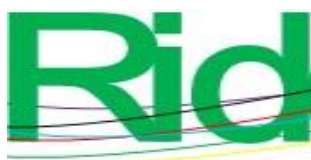

Revista Iberoamericana para la Investigación y el Desarrollo Educativo ISSN 2007 - 7467

Figura 1. Género de los encuestados

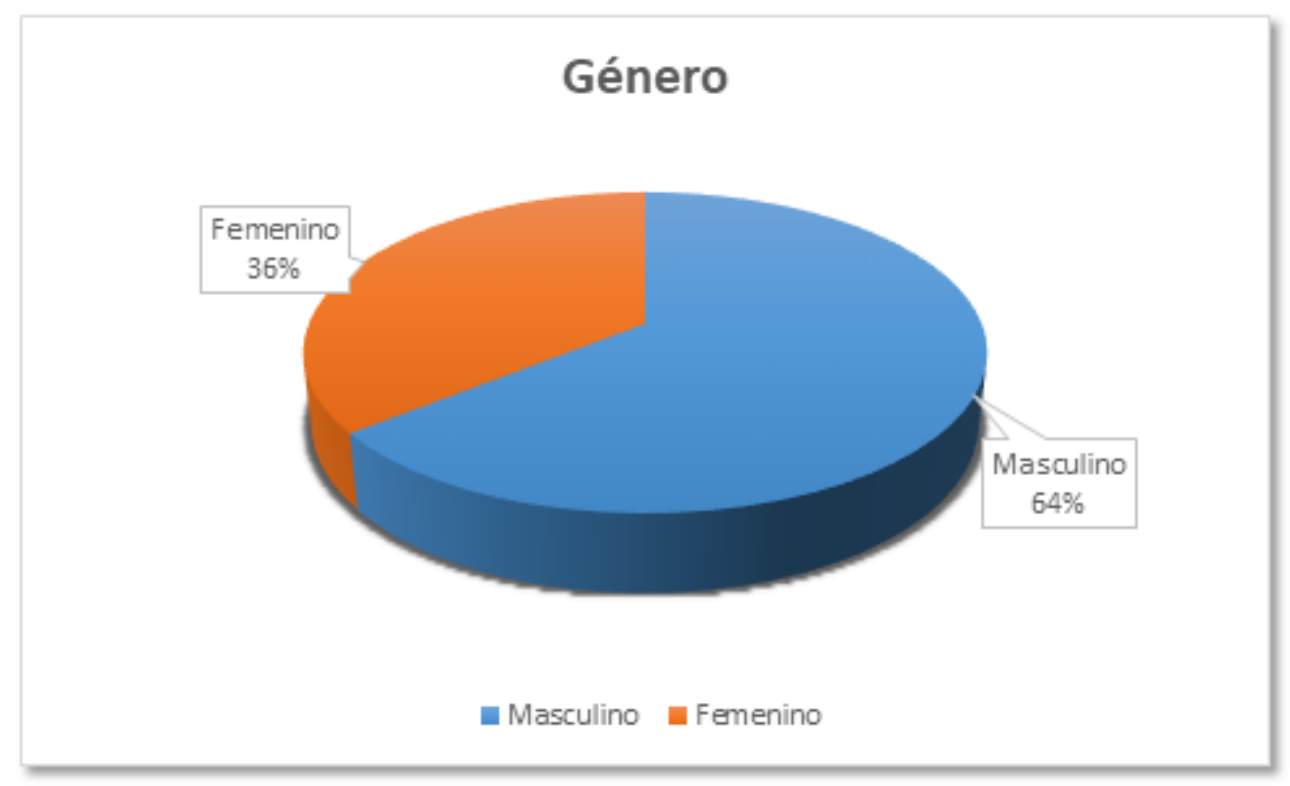

Fuente: Elaboración propia

Figura 2. Edad de los encuestados

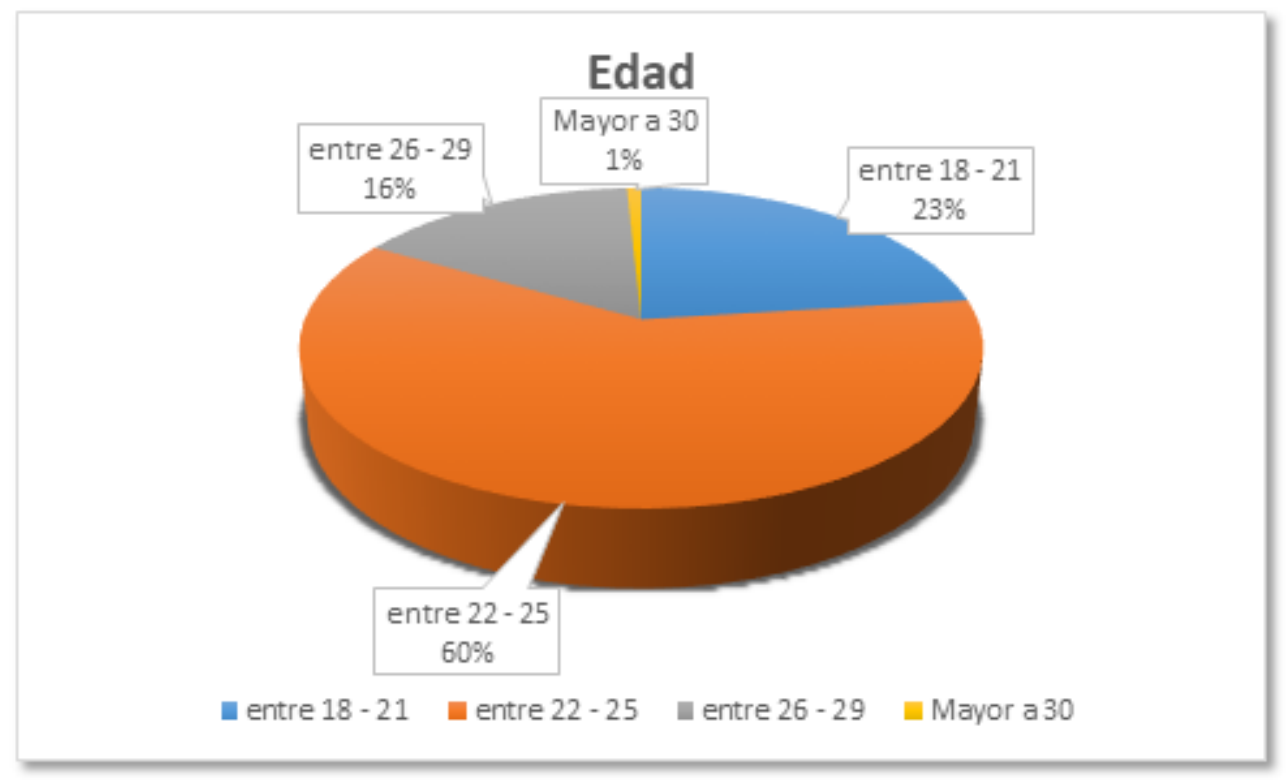

Fuente: Elaboración propia 


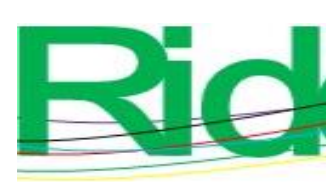

Revista Iberoamericana para la Investigación y el Desarrollo Educativo ISSN $2007-7467$

Figura 3. Avance en programa de estudio

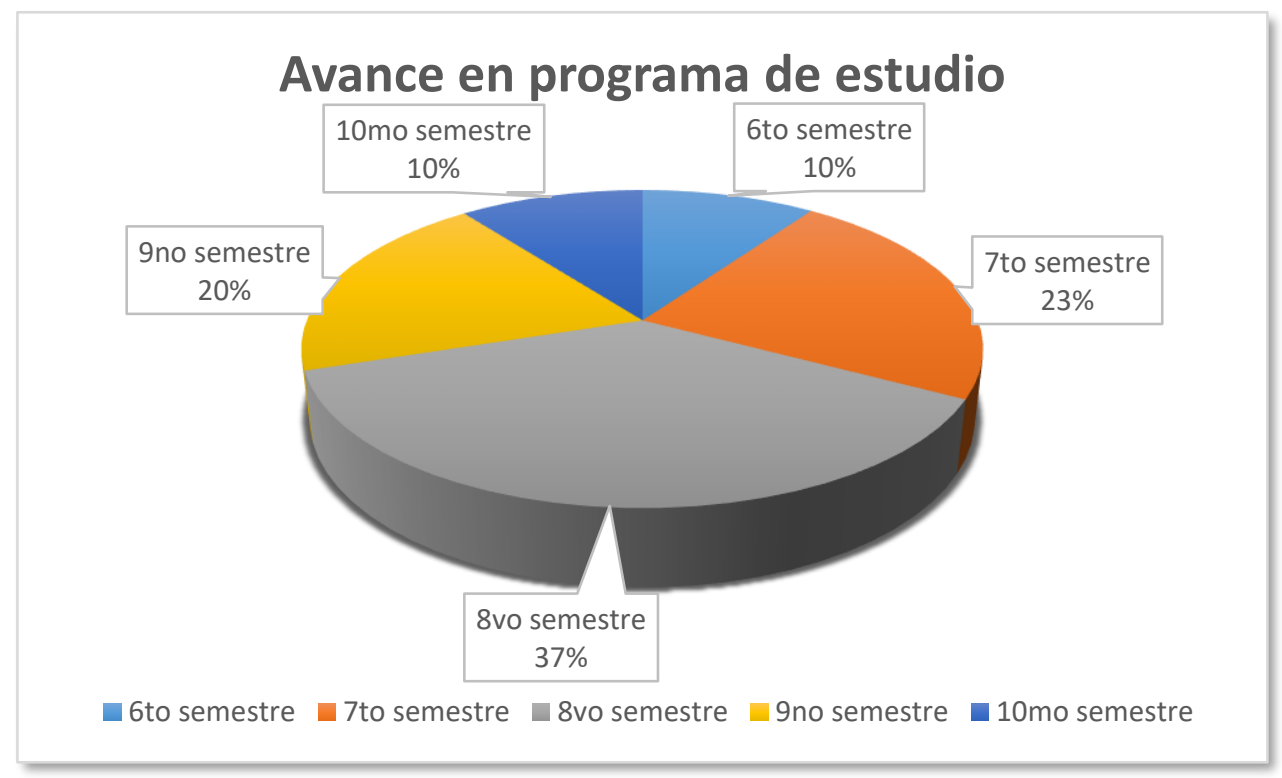

Fuente: Elaboración propia

En principio, se observa que, del total de personas encuestadas, $64 \%$ son hombres y $36 \%$ mujeres (figura 1). En general, dentro de la facultad, se cuenta con prácticamente un equilibrio en cuestiones de género. En la figura 2 se aprecia que $23 \%$ tienen entre 19 y 22 años, $60 \%$ tienen entre 22 y 25 años, $16 \%$ está entre 26 y 29 años y $1 \%$ es mayor a 30 años. Una simple observación que es posible realizar a partir de lo anterior es que esta nueva criptomoneda llamada bitcoin es de mayor interés entre los jóvenes, conocido como millennials, con una participación mayor entre mayores de 18 y menores de 29 años, y esto es medianamente razonable, ya que la criptomoneda fue creada en el año 2009 y, por tanto, es muy nueva para la sociedad, de difícil alcance para generaciones mayores (figura 2). También se observa que $37 \%$ de la muestra cursa su octavo semestre, $23 \%$ está en séptimo y $20 \%$ en noveno, lo que nos da un parámetro amplio del conocimiento y aceptación de las nuevas tecnologías en la formación de profesionales dentro de las licenciaturas que oferta la Facultad de Contaduría Pública de la BUAP (figura 3). 


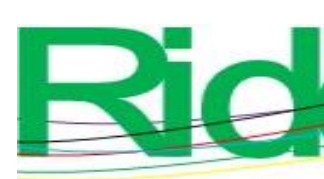

Revista Iberoamericana para la Investigación y el Desarrollo Educativo ISSN $2007-7467$

\section{¿Qué nivel de conocimiento considera que tiene acerca de la criptomoneda bitcoin?}

Figura 4. Nivel de conocimiento acerca de bitcoin

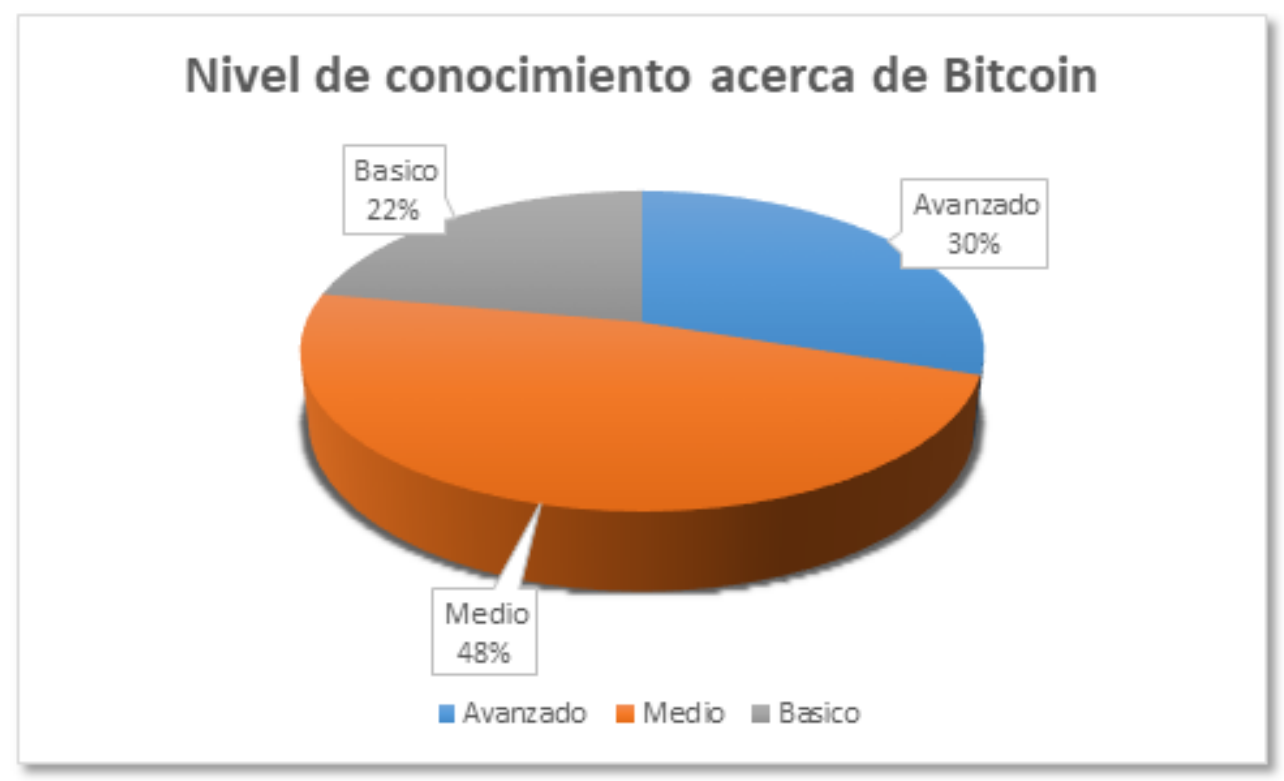

Fuente: Elaboración propia

Del total de las personas encuestadas, $30 \%$ considera que tiene conocimiento avanzado en materia de bitcoin (realiza trading), $48 \%$ respondió sentirse con conocimientos medios (realiza compra de productos o servicios con bitcoin), mientras que $22 \%$ menciona tener conocimientos básicos de operación (conoce el protocolo bitcoin, y tiene cantidades en carteras electrónicas). Esto demuestra que la mayoría de personas encuestadas ha tenido un acercamiento considerable a la terminología de criptomonedas, puesto que el nivel básico se limita a conocimiento general del funcionamiento de estas (figura 4). 


\section{¿Cuál fue el medio por el que conoció el bitcoin?}

Figura 5. Medio por el que conoció el bitcoin

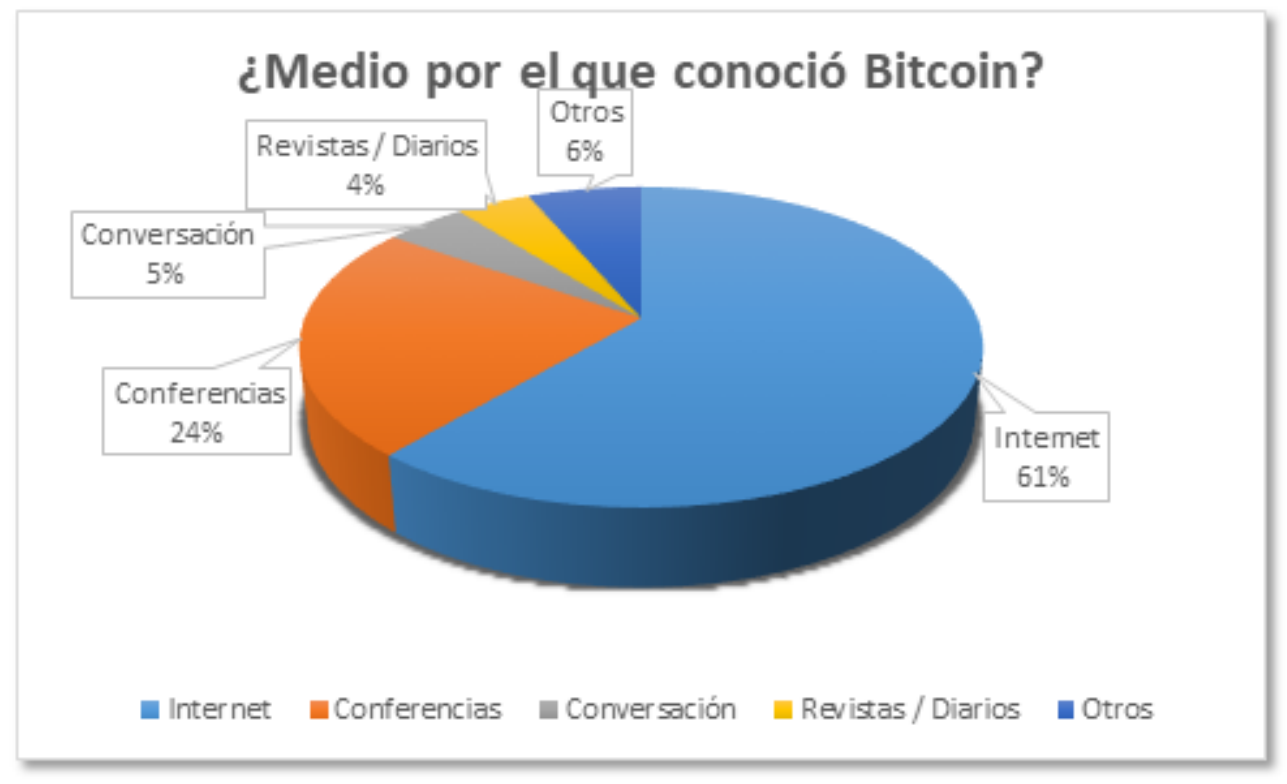

Fuente: Elaboración propia

La mayoría de los participantes que ya conocía esta tecnología, $61 \%$, lo hizo a través del Internet; $24 \%$ se enteró del tema por medio de conferencias y el resto está conformado por conversación informal, $5 \%$, revistas y diarios, $4 \%$, y otras fuentes, $6 \%$ (figura 5). Así pues, como fuente principal se encuentra la navegación por Internet. 


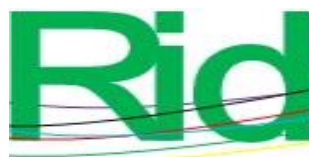

Revista Iberoamericana para la Investigación y el Desarrollo Educativo ISSN 2007 - 7467

\section{¿Sabe usted si bitcoin tiene dueño?}

Figura 6. ¿Bitcoin tiene dueño?

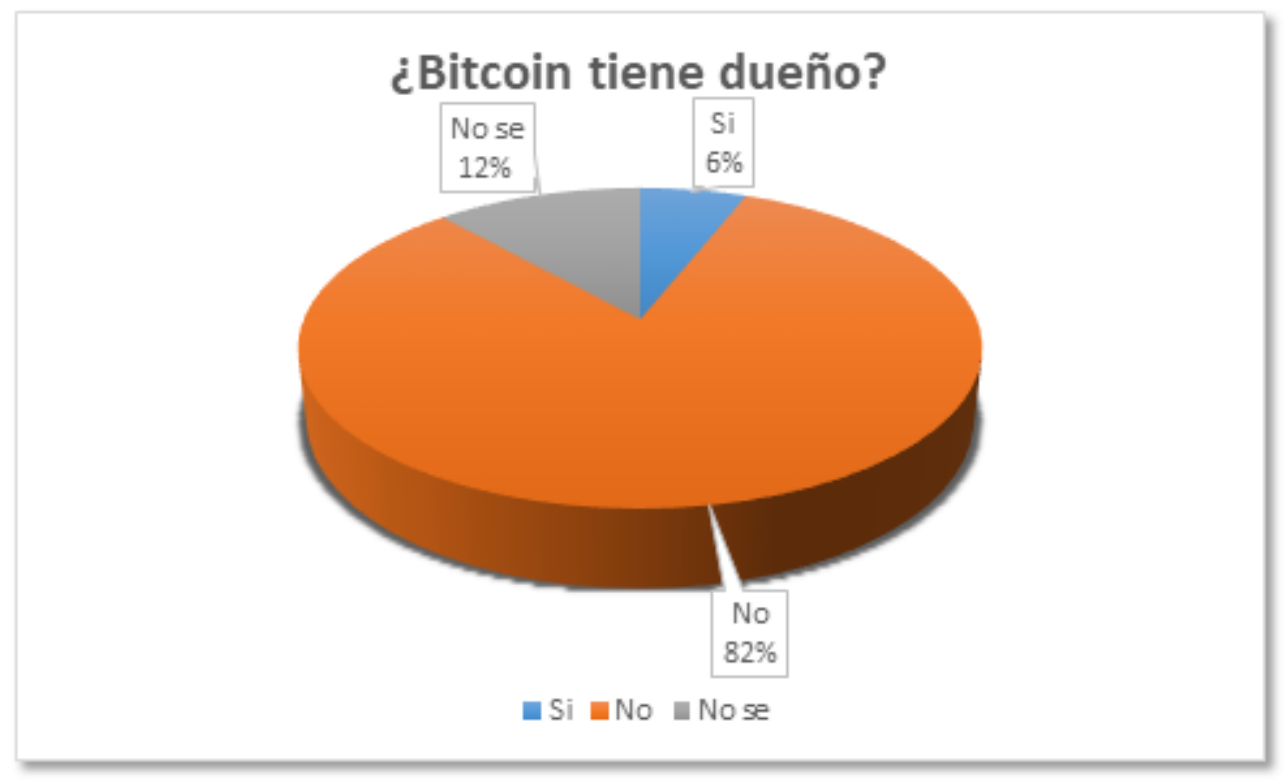

Fuente: Elaboración propia

Esta pregunta resultó interesante, puesto que la principal característica de esta moneda es que no tiene dueño, y se ve reflejada de forma correcta en las respuestas: $82 \%$ respondió que no tiene dueño, $12 \%$ contestó no saber y $6 \%$ afirmó que el bitcoin sí tiene dueño (figura 6). 


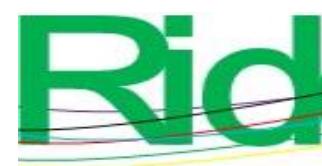

Revista Iberoamericana para la Investigación y el Desarrollo Educativo ISSN 2007 - 7467

\section{Bitcoin no cuenta con respaldo de ningún banco. ¿Esto afecta su confiabilidad como usuario?}

Figura 7. Bitcoin sin respaldo bancario, ¿afecta su confiabilidad?

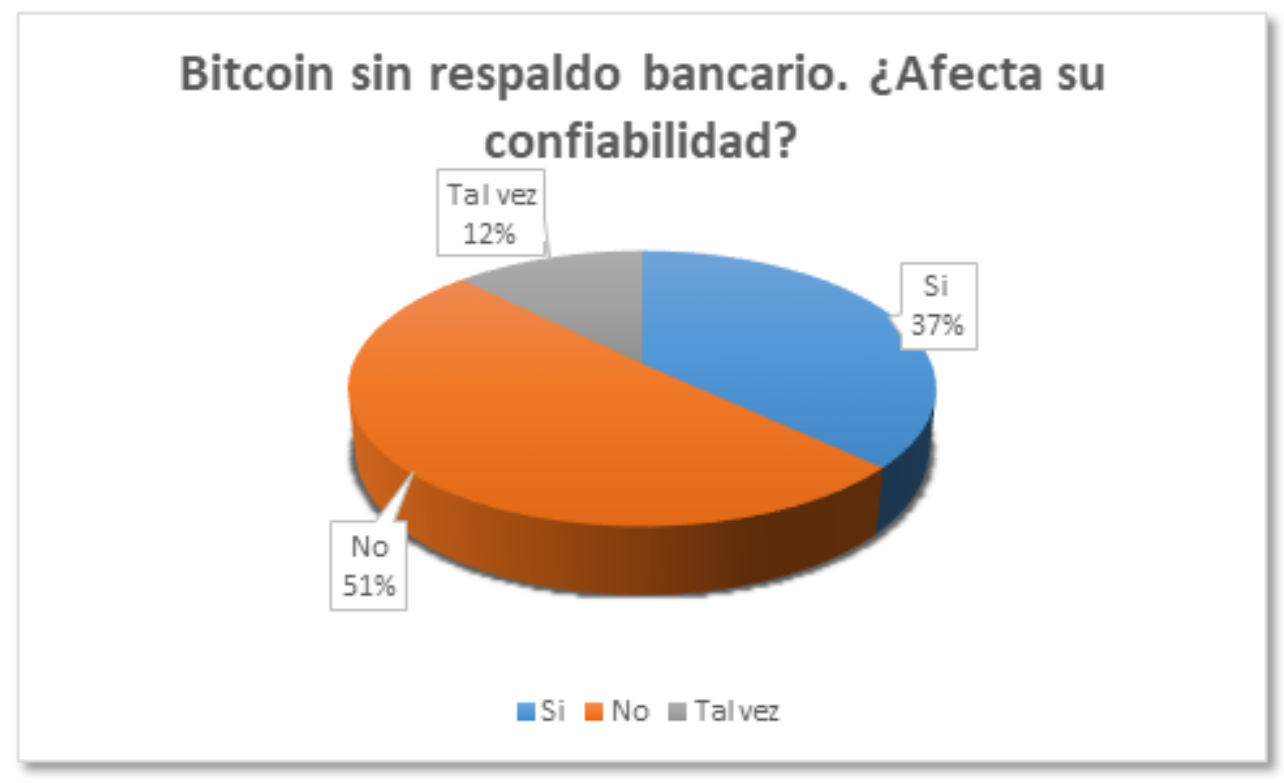

Fuente: Elaboración propia

La independencia del bitcoin afecta en $37 \%$ a la confiabilidad de los usuarios. Por otro lado, $51 \%$ respondió que, a pesar de no tener respaldo bancario, confían en la criptomoneda, mientras que $12 \%$ respondió que tal vez este factor afecte o no a su grado de confianza respecto a esta moneda (figura 7). Sin duda, uno de los paradigmas más fuertes al operar con criptomonedas es la incertidumbre de conocer en quién recae la responsabilidad del manejo de los recursos. 


\section{Desde su punto de vista, ¿cuál es la principal opción que concuerda con el bitcoin?}

Figura 8. Opción que concuerdan con bitcoin

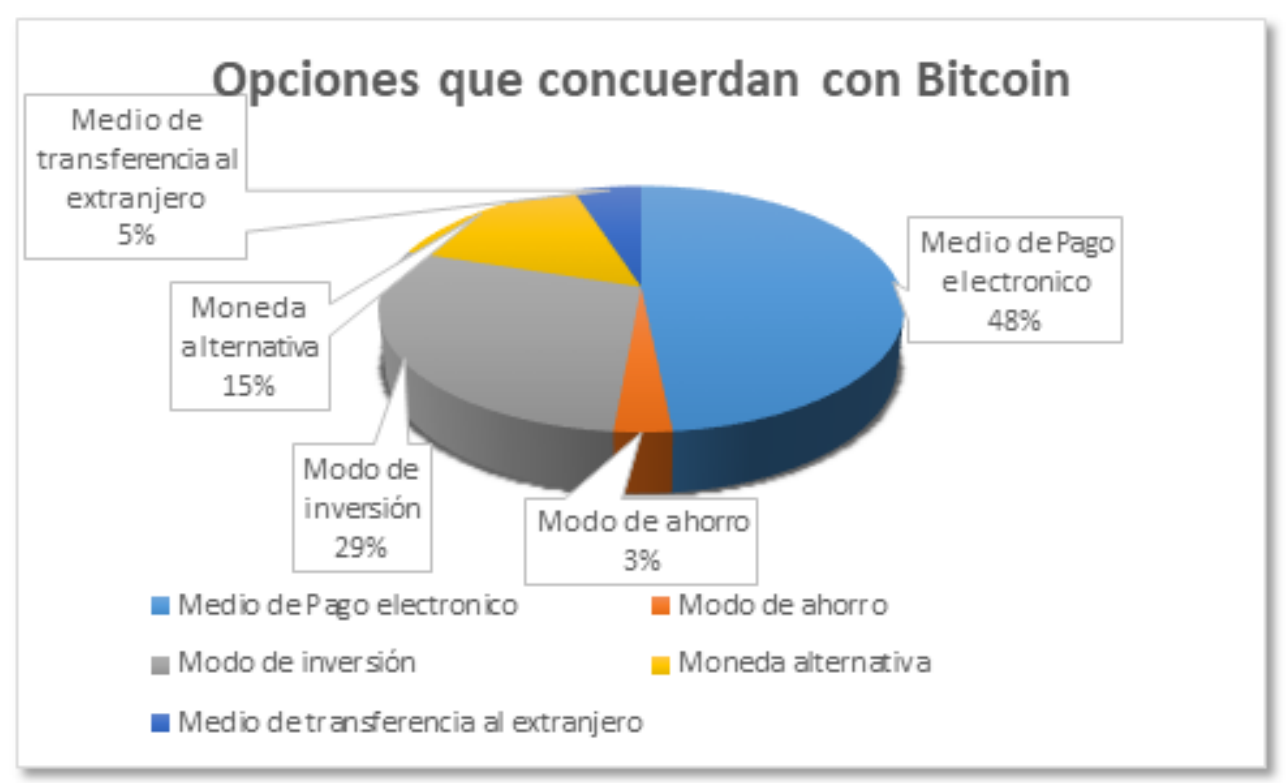

Fuente: Elaboración propia

Esta pregunta se planteó para conocer las principales razones por las que utilizan la criptomoneda. Se encontró que $48 \%$ de personas lo utiliza como medio de pago electrónico, $29 \%$ lo ven como una inversión, $15 \%$ respondió que es una moneda alternativa, $5 \%$ lo identifica como transferencias al extranjero y $3 \%$ lo toma como un ahorro (figura 8 ). 


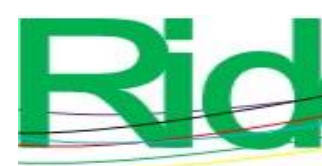

Revista Iberoamericana para la Investigación y el Desarrollo Educativo ISSN $2007-7467$

\section{¿Considera que la criptomoneda bitcoin debe estar regulada?}

Figura 9. Indique si bitcoin debería estar regulado

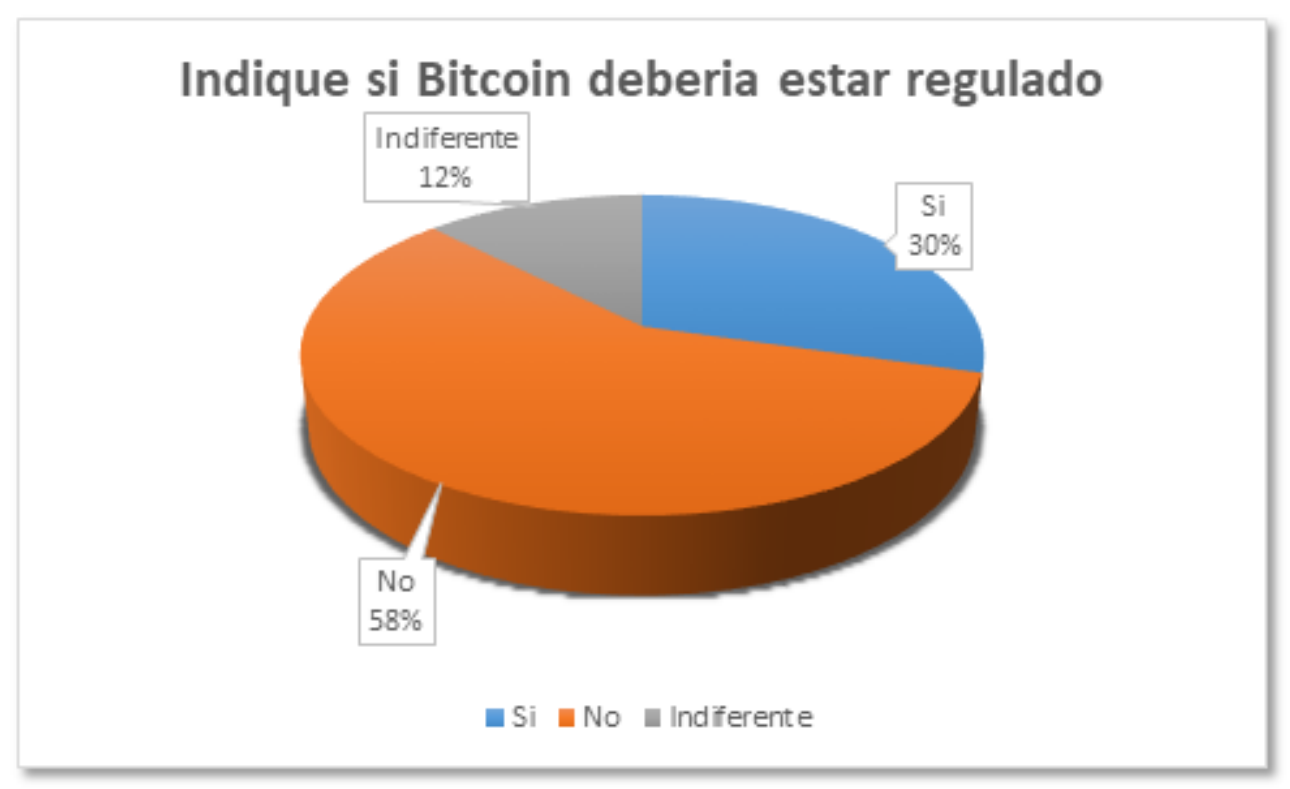

Fuente: Elaboración propia

$30 \%$ de los encuestados se pronunció de forma afirmativa, mientras que 58\% respondió que la criptomoneda no debe ser regulada (a $12 \%$ le fue indiferente la regulación). En México existe ya la regulación para entidades que operan con criptomonedas, sin embargo, no para usuarios finales (Ley Fintech). Recordemos que la característica principal de la moneda es que se rige por la oferta y demanda de los propios usuarios, y, al ser regulada, podría o no afectar a su uso (figura 9). 


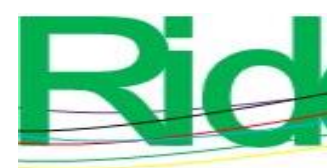

Revista Iberoamericana para la Investigación y el Desarrollo Educativo ISSN $2007-7467$

\section{¿Conoce o ha escuchado mencionar la Ley Fintech?}

Figura 10. Conocimiento de la Ley Fintech

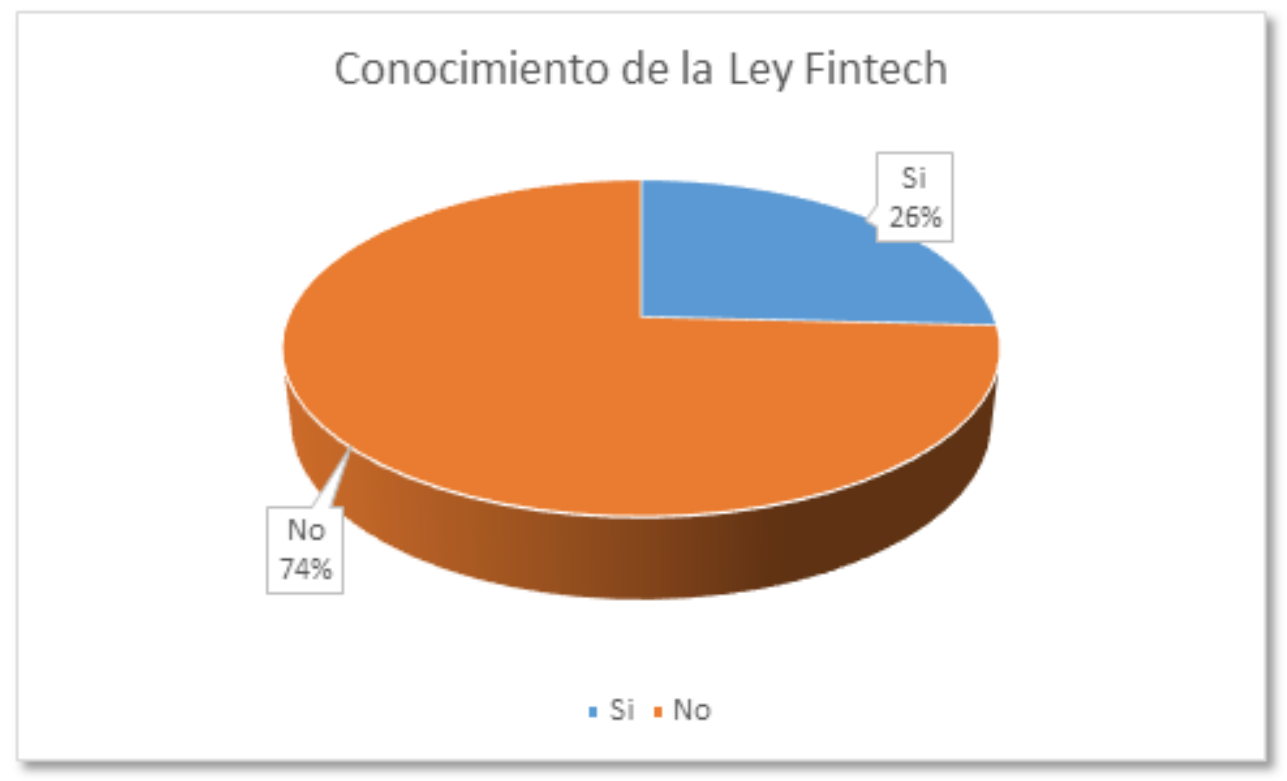

Fuente: Elaboración propia

Al cuestionar a los usuarios sobre el conocimiento de la Ley Fintech, $26 \%$ respondió de forma afirmativa, mientras que $74 \%$ contestó no conocer dicha ley. El ordenamiento al que se hace referencia fue publicado el 9 de marzo de 2018 como medida de control y regulación de criptomonedas, sin embargo, no ha tenido la difusión y por su pronta publicación aún estará sujeta a cambios durante este año (figura 10). 


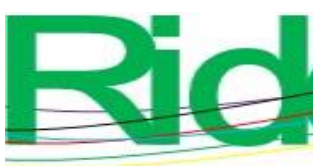

Revista Iberoamericana para la Investigación y el Desarrollo Educativo ISSN 2007 - 7467

\section{¿Cuál es el principal motivo de desconfianza al utilizar bitcoin?}

Figura 11. Motivo de desconfianza al utilizar bitcoin

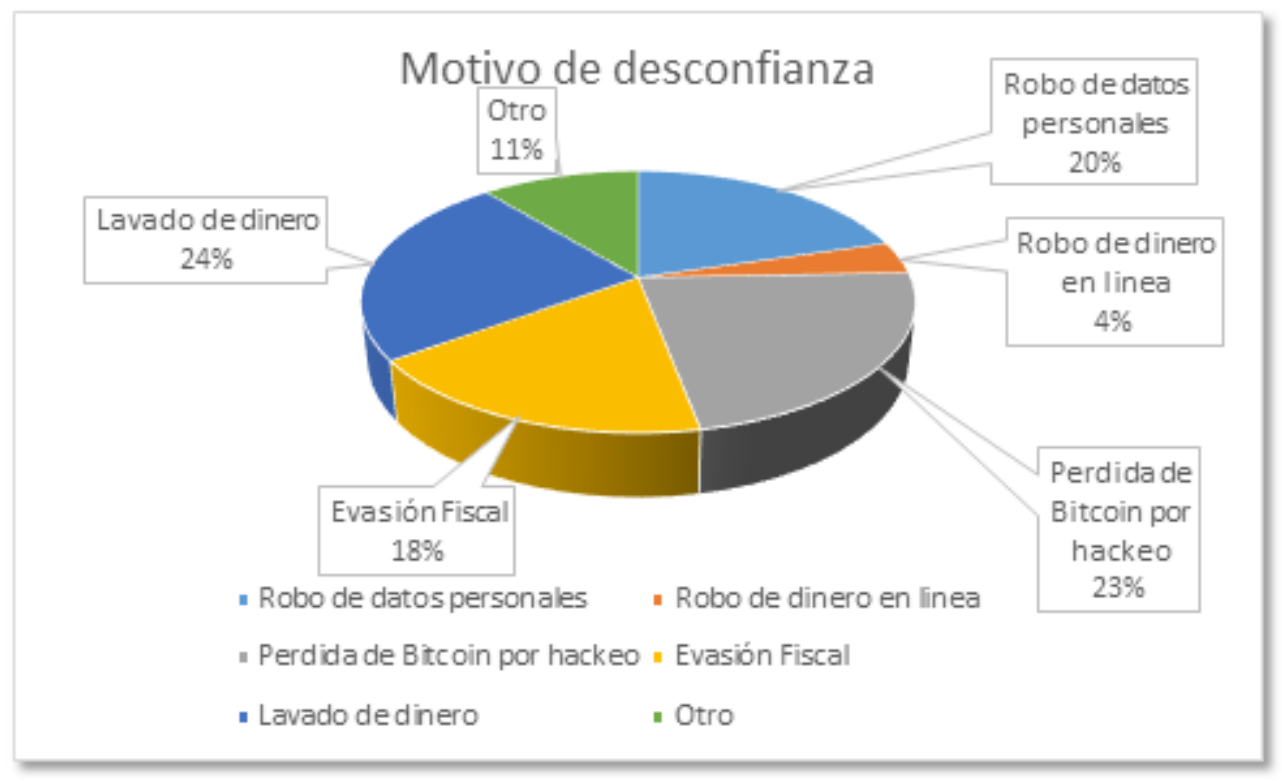

Fuente: Elaboración propia

También se encuestó sobre los principales factores de desconfianza al utilizar las criptomonedas y se obtuvo que a $24 \%$ les suscita sospechas porque está relacionado con el lavado de dinero, $23 \%$ teme perder sus bitcoin por jaqueo, $20 \%$ lo vincula con el robo de datos personales en las transacciones, $18 \%$ lo asimila con actividades de evasión fiscal y $4 \%$ piensa que puede perder su dinero en línea (figura 11). 


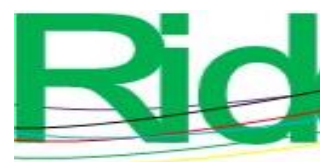

Revista Iberoamericana para la Investigación y el Desarrollo Educativo ISSN $2007-7467$

\section{¿Conoce establecimientos físicos o en línea que operan con Bitcoin?}

Figura 12. Conocimiento de establecimientos que operan con bitcoin

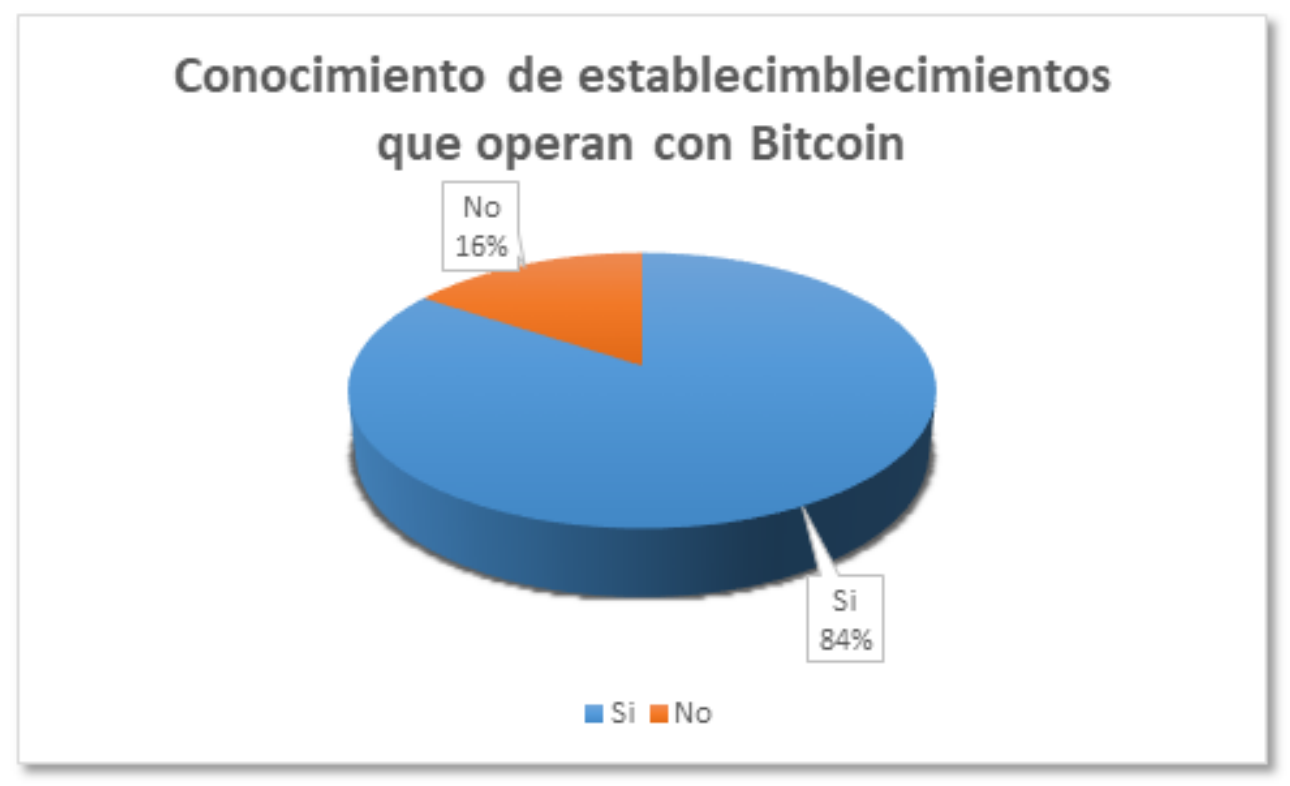

Fuente: Elaboración propia

Ahora bien, $84 \%$ de personas encuestadas afirma conocer establecimientos que operan con bitcoin, por el contrario, $16 \%$ respondió desconocer de estos sitios. Cabe aclarar que muchos de los establecimientos se encuentran en línea. En su mayoría son tiendas de juegos electrónicos o aplicaciones para teléfonos inteligentes (figura 12). 


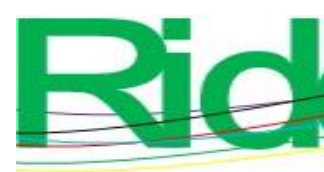

Revista Iberoamericana para la Investigación y el Desarrollo Educativo ISSN $2007-7467$

\section{¿Ha realizado alguna operación con bitcoin?}

Figura 13. Alguna operación con bitcoin

\section{Alguna operación con Bitcoin}

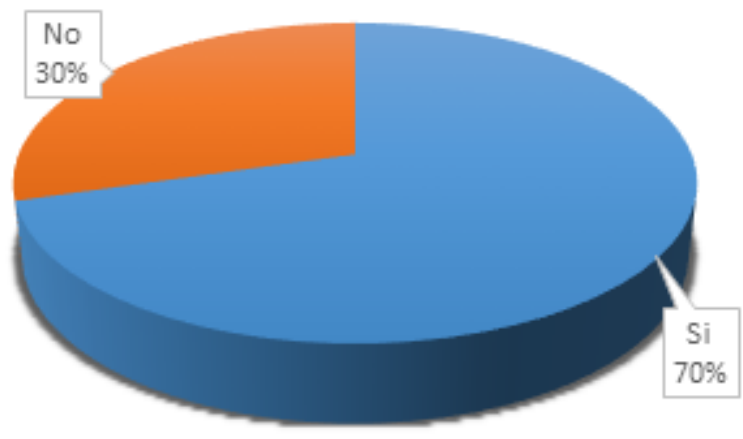

a $\mathbf{\text { Si }}$ No

Fuente: Elaboración propia

En este caso se puede apreciar que $70 \%$ de los encuestados respondió de manera afirmativa, es decir, que por lo menos ha realizado una compra o venta, inversión o ahorro con la criptomoneda bitcoin; mientras que $30 \%$ no ha realizado operaciones, aunque conoce el funcionamiento. Recordemos que la muestra seleccionada se encuentra en un nivel universitario, donde los medios digitales están en explosión (figura 13). 


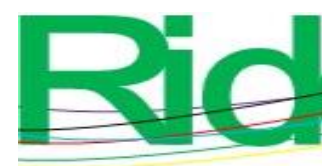

Revista Iberoamericana para la Investigación y el Desarrollo Educativo ISSN $2007-7467$

\section{¿Conoce físicamente un cajero de bitcoin o ha escuchado de su existencia?}

Figura 14. Conoce los cajeros de bitcoin

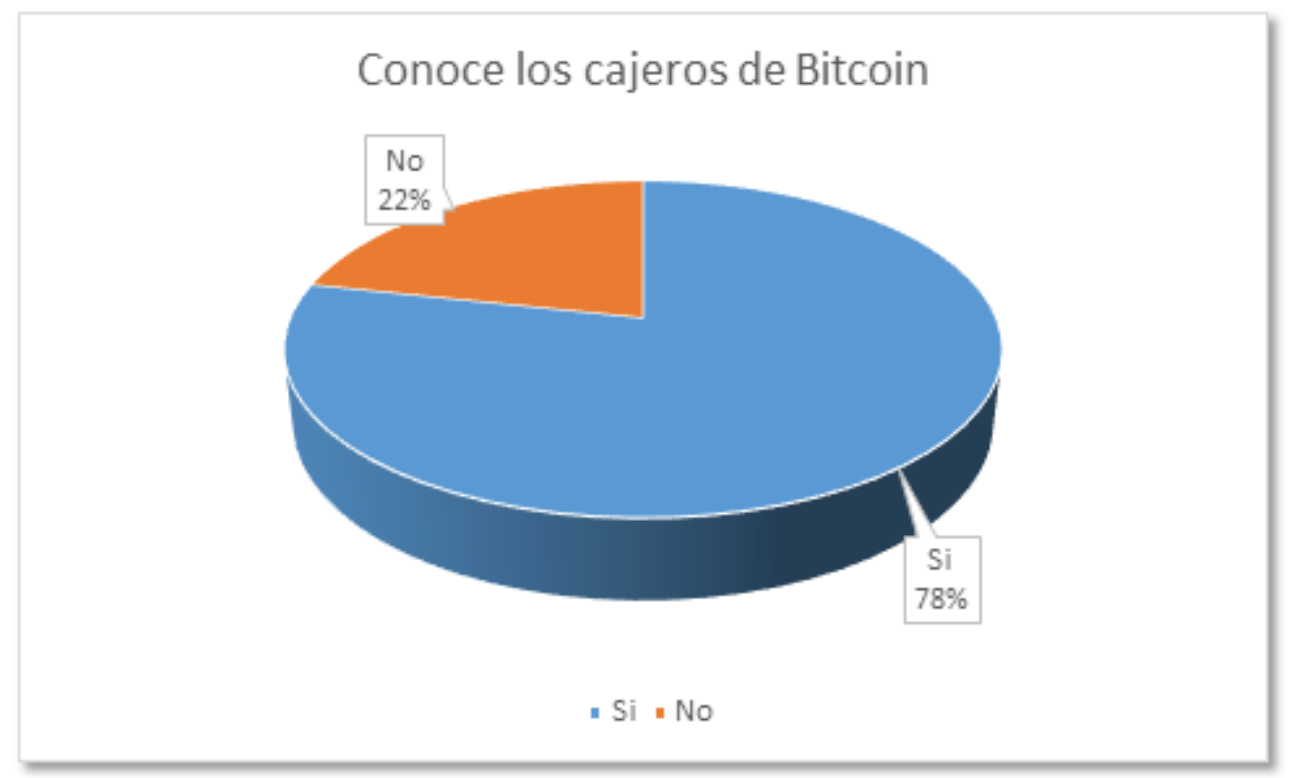

Fuente: Elaboración propia

En la figura 14 se observa que $70 \%$ de los usuarios ha escuchado o conoce los cajeros de bitcoin, mientras que $22 \%$ de los encuestados no los conoce. Los cajeros existen en México desde el año 2014 en Tijuana, Monterrey, Guadalajara, CDMX y Puebla. 


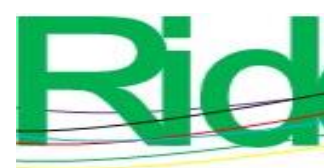

Revista Iberoamericana para la Investigación y el Desarrollo Educativo ISSN $2007-7467$

\section{¿Cuál ha sido su principal fuente para obtener conocimientos relacionados con el bitcoin?}

Figura 15. Fuente de conocimientos adquiridos referentes al bitcoin

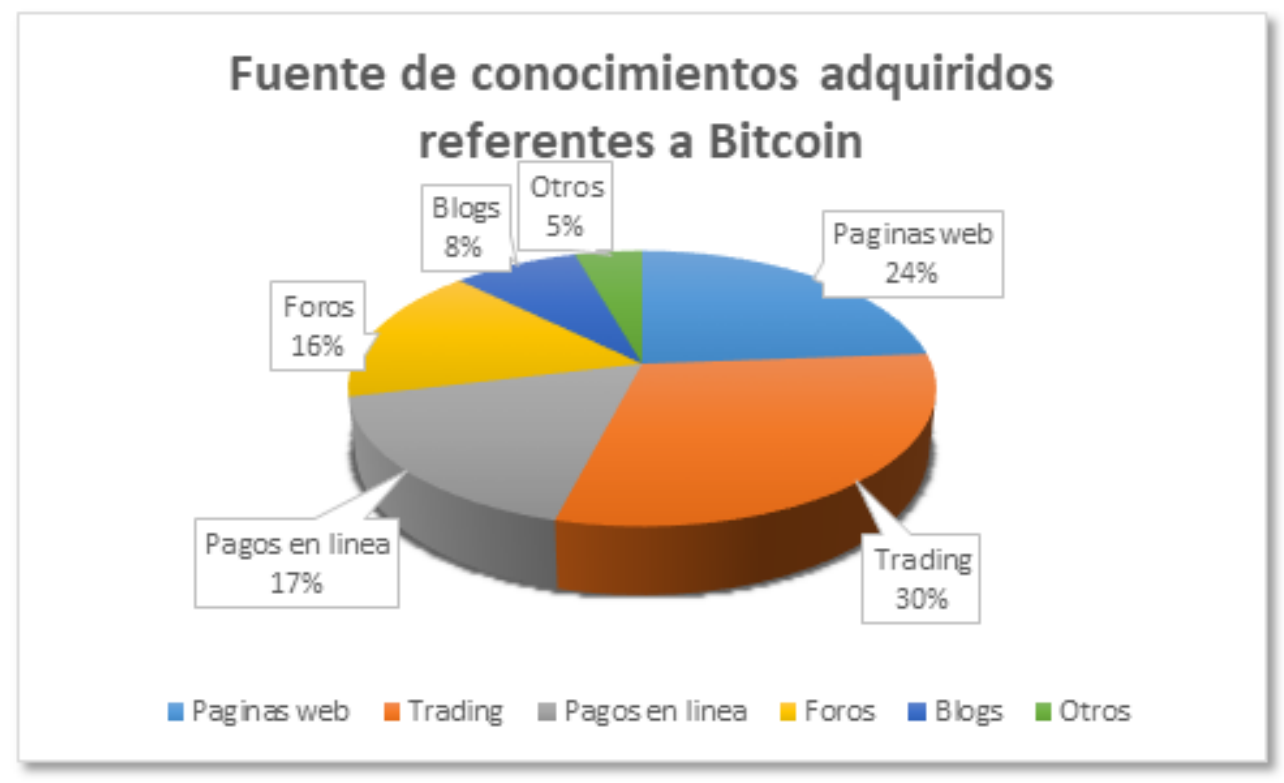

Fuente: Elaboración propia

Aquí $30 \%$ de los encuestados respondió tener conocimientos sobre bitcoin gracias al trading, que consiste en la compra y venta de criptomoneda; $24 \%$ contestó que los conocimientos adquiridos fueron obtenidos de páginas web; $17 \%$ conoció el bitcoin con pagos en línea; $16 \%$ acudió a foros; $8 \%$ en blogs, y $5 \%$ respondió que por otras fuentes. A partir de la alza registrada en el mes de diciembre de 2017, las personas buscaron la oportunidad de ganar dinero, por lo que realizaron compra y venta de esta criptomoneda, lo que les llevó al mundo del trading (figura 15). 


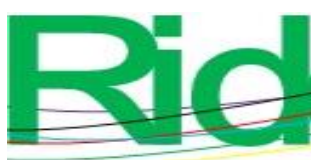

Revista Iberoamericana para la Investigación y el Desarrollo Educativo ISSN 2007 - 7467

\section{Número de aplicaciones instaladas en su teléfono inteligente relacionadas con criptomonedas}

Figura 16. Aplicaciones instaladas relacionadas con criptomonedas

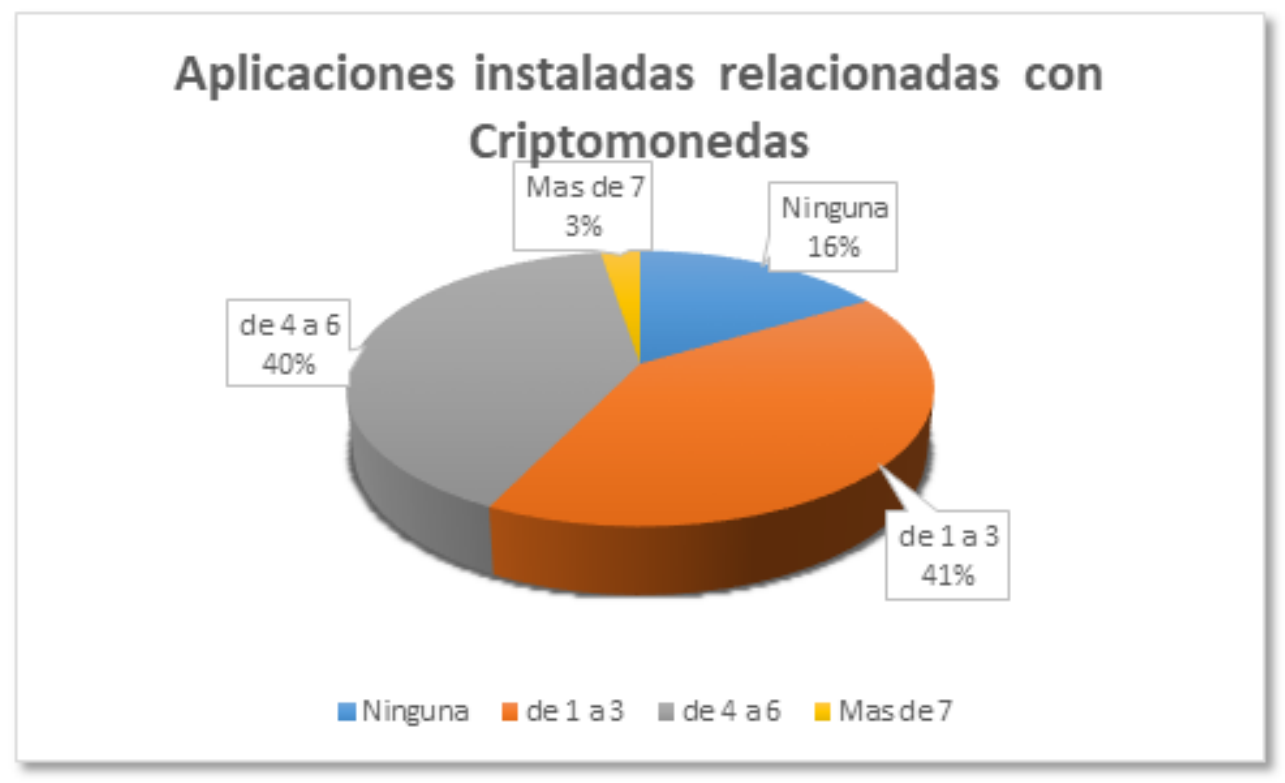

Fuente: Elaboración propia

El $16 \%$ de los encuestados respondió no tener aplicaciones en sus teléfonos inteligentes relacionadas con las criptomonedas, mientras que $84 \%$ por lo menos cuenta con una aplicación. La aplicación con más descargas corresponde a las billeteras electrónicas ( $e$ wallet), instrumento que se utiliza para enviar y recibir criptomonedas, seguida de aplicaciones para consultar las cotizaciones en tiempo real del bitcoin (figura 16). 


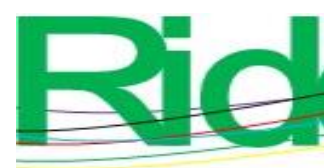

Revista Iberoamericana para la Investigación y el Desarrollo Educativo ISSN 2007-7467

\section{¿Conoce algún curso o diplomado referente a criptomonedas?}

Figura 17. Conocimiento de cursos o diplomados referente a criptomonedas

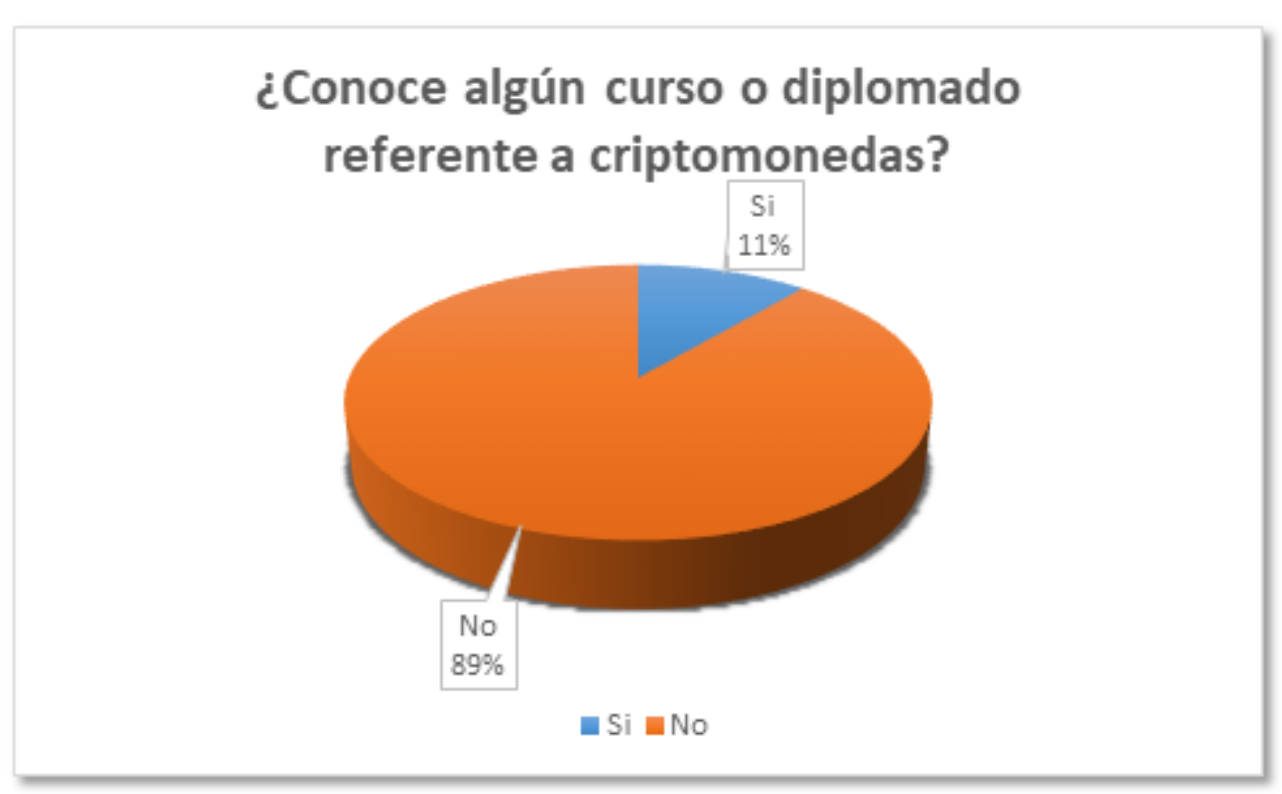

Fuente: Elaboración propia

Como parte del objetivo de esta investigación, esta pregunta se formuló en el sentido de saber el área de oportunidad creada a partir de esta criptomoneda. Así, 11 \% respondió conocer algún curso o diplomado, mientras que $89 \%$ contestó de forma negativa. Generalmente, los cursos y diplomados ofrecidos referentes a criptomonedas en Internet están condicionados a un registro de usuarios, quienes caen cautivos en robos o fraudes por empresas que manejan un modelo piramidal, las cuales exigen el ingreso de otros usuarios para el retiro de su inversión (figura 17). 


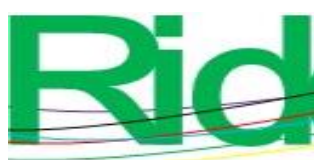

Revista Iberoamericana para la Investigación y el Desarrollo Educativo ISSN $2007-7467$

\section{¿Cree que es necesario incluir temas referentes a criptomonedas en el plan de estudio de las licenciaturas de la Facultad de Contaduría Pública de la Benemérita Universidad Autónoma de Puebla?}

Figura 18. Importancia de incluir temas referentes a criptomonedas en plan de estudio

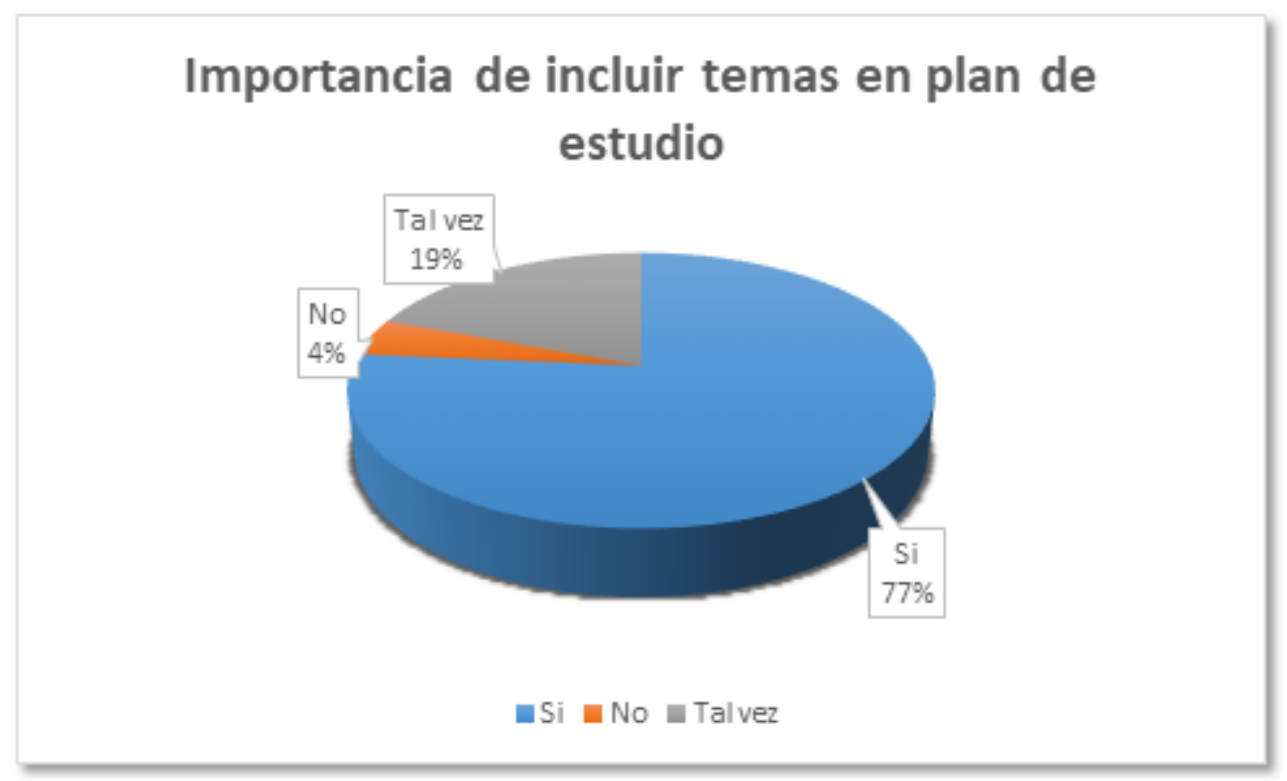

Fuente: Elaboración propia

Si analizamos esta gráfica podemos observar que a $96 \%$ de los encuestados les resulta de suma importancia incluir en los planes de estudio los temas relacionados con criptomonedas. Al ser un medio de pago válido y aceptado, las instituciones educativas, directivos y docentes deberán estar involucrados en la modificación de los programas de estudio para las futuras generaciones (figura 18). 


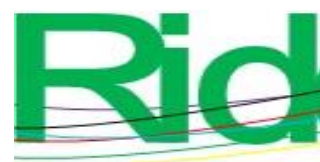

Revista Iberoamericana para la Investigación y el Desarrollo Educativo ISSN 2007 - 7467

\section{¿Realizaría una licenciatura o estudio de posgrado referente al bitcoin?}

Figura 19. Realizar estudios a nivel licenciatura o posgrado referente a bitcoin

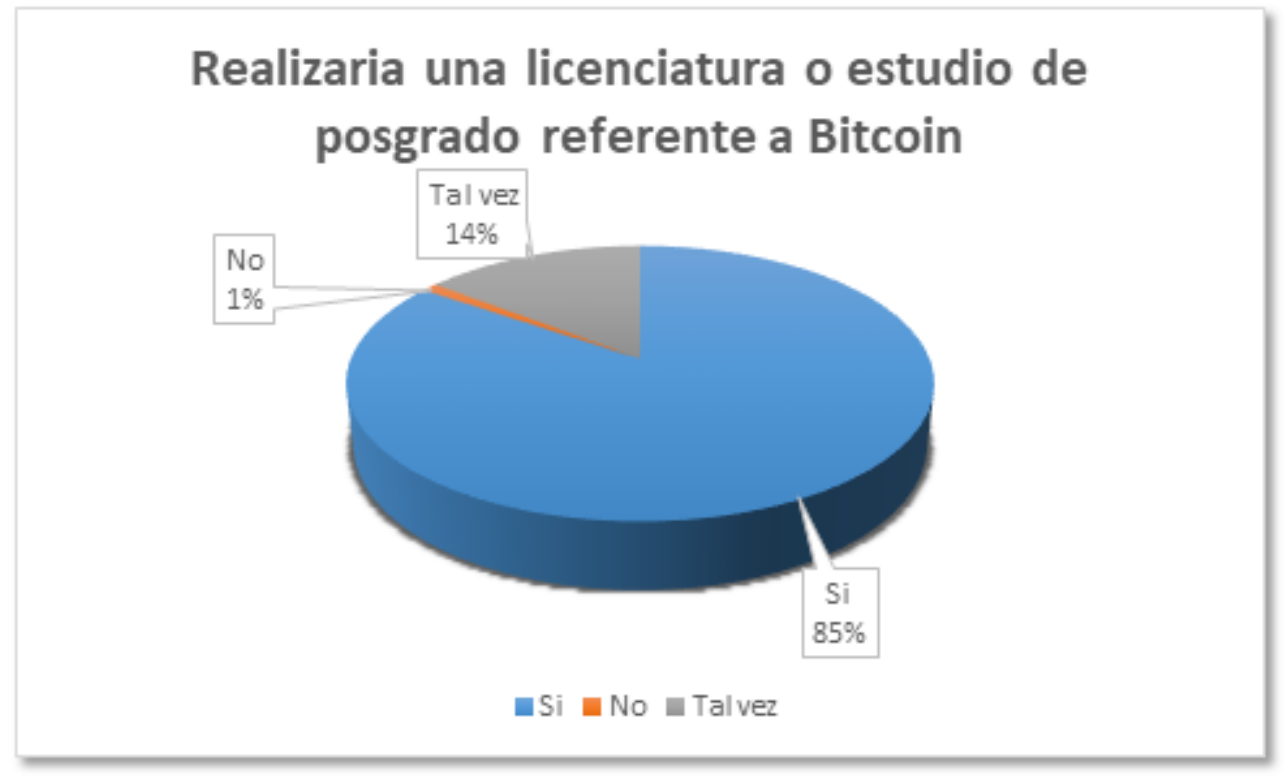

Fuente: Elaboración propia

En este caso, $85 \%$ de los encuestados respondió de manera afirmativa al interés de estudiar alguna licenciatura o estudios de posgrados referente a criptomonedas, $14 \%$ contestó que tal vez y solo $1 \%$ manifestó no realizar estudios en esta área. Si analizamos de manera general, tenemos que $99 \%$ de los encuestados está interesados en este tema, lo cual nos lleva a foco de ateción para educación nacional, pues al no contar con licenciaturas y estudios de posgrado en esta área en México buscarán la alternativa en el extranjero (figura 19). 


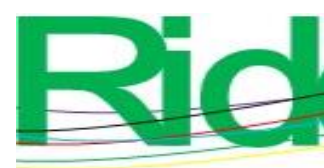

Revista Iberoamericana para la Investigación y el Desarrollo Educativo ISSN $2007-7467$

\section{¿Qué modalidad prefiere para realizar un estudio profesional de bitcoin?}

Figura 20. Modalidad de preferencia de estudio relativa al bitcoin

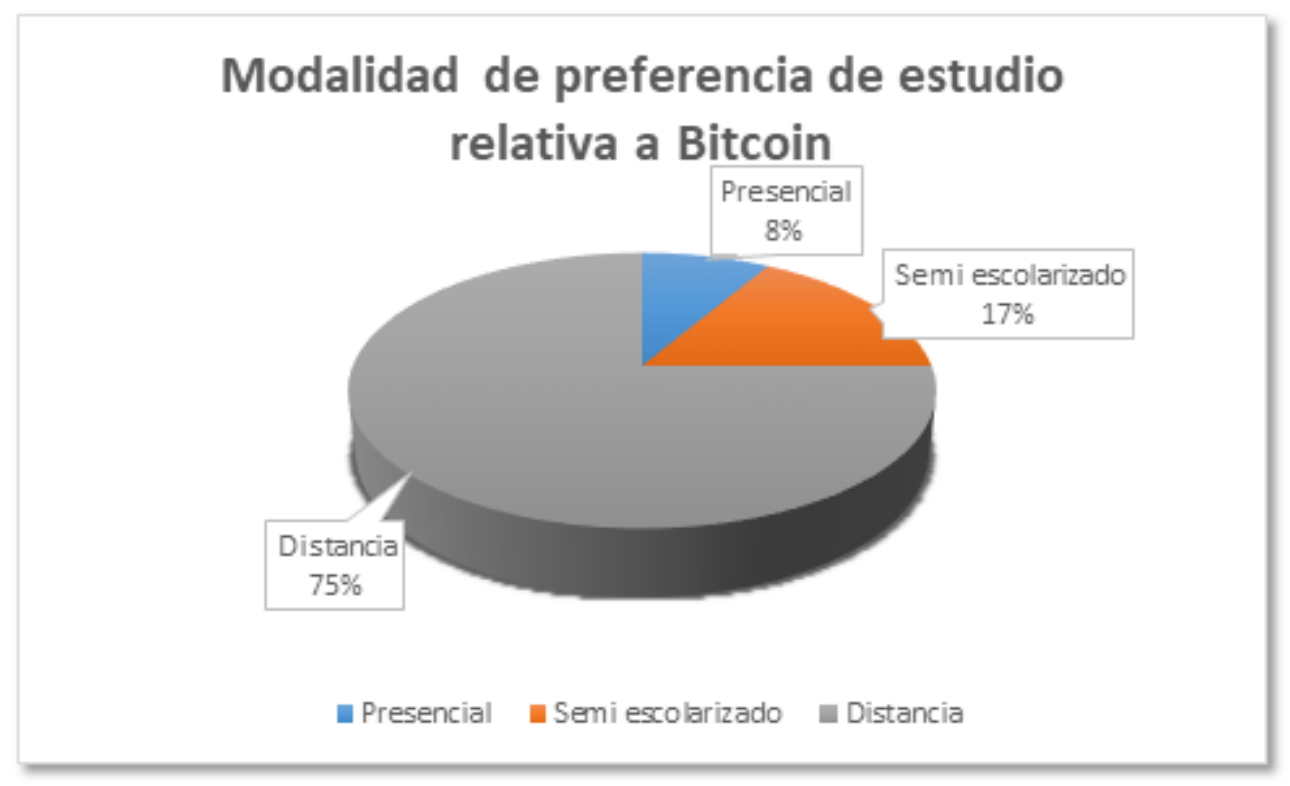

Fuente: Elaboración propia

En la figura 20 se observa que $8 \%$ se inclina por una preferencia de estudio de forma tradicional, es decir, presencial, $17 \%$ opta por una modalidad semiescolarizada, con un mentor o tutor que lo guíe en esta área del conocimiento en criptomonedas, y 75 \% respondió que la mejor forma de estudio es a distancia. El ritmo acelerado en la preparación de profesionistas nos lleva a adaptar los nuevos programas a modalidad a distancia, debido a las habilidades desarrolladas de esta generación que sin duda se caracteriza por ser autodidactas. Adicionando a este argumento, la mejor forma de entender la criptomoneda es operar con ella de forma práctica (figura 20).

\section{Discusión}

En esta investigación se concluye que es necesario modificar los programas de estudio a nivel licenciatura de la Facultad de Contaduría Pública de la Benemérita Universidad Autónoma de Puebla, debido a los cambios y exigencias del mercado económico, y con ello contribuir a que las empresas y los usuarios de criptomonedas gocen de una seguridad y no de incertidumbre en las operaciones. 


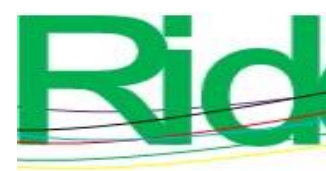

Revista Iberoamericana para la Investigación y el Desarrollo Educativo ISSN 2007 - 7467

Se observó que no existe hasta el día de hoy una institución educativa en México que ofrezca una carrera relacionada con criptomonedas y mucho menos un estudio de posgrado. Así pues, es un área de oportunidad para las universidades y, desde ahí, hacer frente a las exigencias de las nuevas tecnologías en educación y comercio financiero. Si bien es cierto que ya se opera con criptomonedas en México, aún faltan criterios de registros contables y técnicas para su identificación y fiscalización.

Sin duda hay que tomar en consideración que la principal fuente de conocimientos que hasta el momento tienen los usuarios es la consulta de páginas web, o directamente incursionar en el trading (compra-venta de bitcoins), por lo que es necesario contar con cursos, diplomados y carreras dirigidos en esta área.

Es notoria también la inclinación de las generaciones a las nuevas tecnologías de información y comunicación, puesto que son los principales motores de esta criptomoneda, al utilizarla de forma regular para operaciones entre otras personas (persona a persona) por medio de aplicaciones instaladas en sus teléfonos inteligentes.

Se concluye, de igual forma, que al elaborar un programa de estudio referente a criptomoneda se estaría ofreciendo una nueva oportunidad a las nuevas generaciones de formarse de manera profesional con mayores oportunidades para el ejercicio de su carrera. Respecto a los objetivos planteados, se concluye que, con la presente investigación, se llegó a conocer, evaluar y analizar el manejo de la criptomoneda bitcoin, y se determinaron las ventajas y desventajas al utilizarla como medio de pago. A partir de todo lo anterior fue posible diseñar una propuesta temática que sirva de base a las universidades nacionales en sus futuros planes de estudio. 


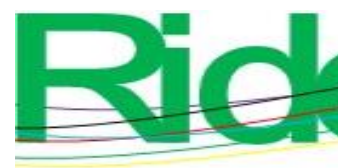

Revista Iberoamericana para la Investigación y el Desarrollo Educativo ISSN $2007-7467$

\section{Conclusiones}

Acostumbrados ya a los cambios tecnológicos en periodos muy cortos, el bitcoin alcanzó rápidamente popularidad en los usuarios para ser usada como medio de pago electrónico. Esto debido a que ofrece una seguridad mayor a la que ofrecen las transferencias electrónicas; reduce fraudes, robo de contraseñas y la clonación de tarjetas de crédito, que representaban un alto importe en pérdidas familiares y empresariales.

Una razón más para usar el bitcoin es permitir a las páginas un sistema de fideicomiso, regulado con la ya aprobada Ley Fintech. Con esto se asegura que la persona que venda reciba el pago, siempre y cuando la mercancía llegue a su destino, tal y como lo manejan algunas páginas conocidas de subasta y segunda mano.

Enviar dinero a otras partes del mundo va a acompañada de una comisión o cobro por el servicio de envío; al manejar bitcoin se eliminan intermediarios y el dinero virtual llega íntegro y completo (razón por la cual se verán afectadas empresas que se dedican al envió de dinero o divisas a diferentes regiones e incluso países, como lo es el caso del envío de dólares a México por trabajadores mexicanos en Estados Unidos).

Existe ya una amplia aceptación del bitcoin en muchos países. En México se empiezan a despuntar los primeros índices en la utilización del bitcoin como moneda de pago. Y la prueba la tenemos en aperturas de casas de cambio y cajeros automáticos de bitcoins. Seguramente, en un tiempo no muy lejano, enviar y recibir bitcoins será muy similar a lo que ahora realizamos al enviar y recibir correos electrónicos: de manera sencilla y segura.

Ahora bien, habiendo gente ya operando en México con bitcoins, portales que ofrecen artículos y servicios y aceptan bitcoin como medio de pago, casas de cambio y cajeros automáticos de bitcoin, podemos decir que existen las suficientes razones para utilizar bitcoin como medio de pago, con cautela y con medida mientras se vaya conociendo la moneda.

Es necesario, entonces, una educación financiera basada en criptomonedas para el conocimiento y uso del bitcoin en México, pues, como ya se mencionó, la circulación y aceptación como forma de pago en diversos establecimientos está ya en el camino, si bien largo, de generalizarse. 


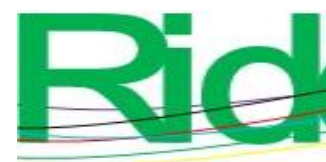

Revista Iberoamericana para la
Investigación y el Desarrollo Educativo
ISSN $2007-7467$

\section{Futuras líneas de investigación}

Derivado del presente estudio, se considera que esta investigación fue aplicada a alumnos de la Facultad de Contaduría Publica de la Benemérita Universidad Autónoma de Puebla, dando la pauta a futuras líneas de investigación para aplicar otras instituciones del país con trabajos complementarios sobre el tema, tales como regulación de criptomonedas, aceptación como medio de pago, regulación contable y fiscal, así como funcionamiento de blockchain en las finanzas empresariales.

\section{Recomendaciones}

Tratar de entender el funcionamiento de la minería puede ser complicado, por lo se sugiere el acompañamiento de un experto en informática, así como experto en redes. Como resultado de esta investigación, se incluye el siguiente temario para iniciar un programa de estudio, o un MOOC, que afronte el reto de esta criptomoneda.

\section{Propuesta de temario}

- Módulo 1: Concepto de bitcoin:

- ¿Qué son las monedas digitales?

- El atractivo del bitcoin.

- Riesgos del bitcoin.

- Módulo 2: funcionamiento del bitcoin:

- ¿Qué es el blockchain y qué seguridad ofrece?

- ¿Cómo convertirse en minero?

- Otros conceptos técnicos de bitcoin.

- Naturaleza anónima del bitcoin.

- ¿Cómo se crean los Bitcoin?

- Módulo 3: nuevas oportunidades de negocio:

- Sectores más favorecidos.

- Modelos de negocio.

- Módulo 4: perspectivas a largo plazo:

- El presente del bitcoin.

- El futuro del bitcoin. 
- Módulo 5: caso práctico:

- Bitcoin y el negocio.

- Bitcoin y el cliente.

- Módulo 6: bitcoin como moneda:

- ¿Cómo obtener bitcoins?

- ¿Qué es un monedero?

- ¿Cómo pagar con bitcoins?

- ¿Cómo aceptar bitcoins?

- ¿Dónde puedes usar bitcoins?

- Módulo 7: Ley Fintech:

- ¿Qué, quién y por qué?

- Regulación fiscal en México.

- Regulación en otros países.

- Sanciones.

- Módulo 8: normas de información financiera

- Normas internacionales.

- Normas nacionales.

- Registros contables. 


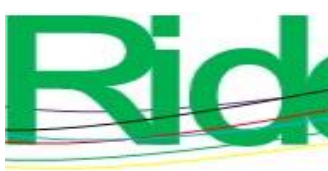

Revista Iberoamericana para la Investigación y el Desarrollo Educativo ISSN $2007-7467$

\section{Referencias}

Adriano, A. y Monroe, H. (2016). Internet de confianza. Finanzas y Desarrollo. Recuperado de http://www.imf.org/external/pubs/ft/fandd/spa/2016/06/pdf/adriano.pdf.

Antonopoulos, A. (24 de noviembre 2020). Bjgtjme, Bitcoin: El fin del dinero tal y como lo conocemos. Recuperado de https://www.youtube.com/watch?v=aPzW2kzs88I

Bit2Me Academy. (17 de diciembre de 2017). Precio histórico del bitcoin. Recuperado de https://academy.bit2me.com/precio-historico-bitcoin/.

elbitcoin.org. (24 de enero de 2013). Preguntas frecuentes acerca de bitcoin. Recuperado de https://elbitcoin.org/bitcoin-preguntas-frecuentes/\#II.

El Financiero. (1 de marzo de 2018). 10 puntos para entender la nueva Ley Fintech. El Financiero. Recuperado de http://www.elfinanciero.com.mx/empresas/diez-puntospara-entender-la-nueva-ley-fintech.

Fernández, M. (30 de diciembre de 2017). En medio de la fiebre del bitcoin, lanzan una carrera sobre criptoeconomía en Buenos Aires. Infobae. Recuperado el de https://www.infobae.com/educacion/2017/12/30/en-medio-de-la-fiebre-del-bitcoinlanzan-una-carrera-sobre-criptoeconomia-en-buenos-aires/.

Huffpost México. (17 de junio de 2017). Estos empresarios mexicanos ya abrieron las puertas al futuro del Bitcoin. Huffpost México. Recuperado de https://www.huffingtonpost.com.mx/2017/06/18/estos-empresarios-mexicanos-yaabrieron-las-puertas-al-futuro-de_a_22488011/.

Jiménez, D. (19 de abril de 2020). The Real bitcoin Club: cómo vivir usando solo criptomonedas durante 2 años. Cointelegraph en Español. Recuperado de https://es.cointelegraph.com/news/the-real-bitcoin-club-how-to-live-using-onlycryptocurrencies-for-2-years.

LocalBitcoins.com. (2018). Buy and sell bitcoins near you. Retrieved from https://localbitcoins.com/es/.

Nakamoto, S. (Ocubre 31, 2008). Bitcoin P2P e-cash paper. The Cryptography Mailing List. Retrieved from http://www.metzdowd.com/pipermail/cryptography/2008October/author.html.

Palacios, Z., Vela, M. y Tarazona, G. (2015). Bitcoin como alternativa transversal de intercambio monetario en la economía digital. Redes de Ingeniería, 6(1), 106-128. 
Recuperado

https://revistas.udistrital.edu.co/ojs/index.php/REDES/article/view/8617/10531.

Presidencia de la República. (9 de Marzo de 2018). Decreto por el que se expide la Ley para Regular las Instituciones de Tecnología Financiera y se reforman y adicionan diversas disposiciones de la Ley de Instituciones de Crédito, de la Ley del Mercado de Valores, de la Ley General de Organizaciones y Actividades Auxiliares del Crédito, de la Ley para la Transparencia y Ordenamiento de los Servicios Financieros, de la Ley para Regular las Sociedades de Información Crediticia, de la Ley de Protección y Defensa al Usuario de Servicios Financieros, de la Ley para Regular las Agrupaciones Financieras, de la Ley de la Comisión Nacional Bancaria y de Valores y, de la Ley Federal para la Prevención e Identificación de Operaciones con Recursos de Procedencia Ilícita. Diario Oficial de la Federación. Recuperado de http://www.dof.gob.mx/nota_detalle.php?codigo=5515623\&fecha=09/03/2018.

Pozzi, S. (6 de octubre de 2011). Muere Steve Jobs, fundador de Apple. El País. Recuperado de https://elpais.com/tecnologia/2011/10/06/actualidad/1317891661_850215.html.

Ramos, F. (2014). Bitcoinomics. ¿Puede un sistema bancario de reservas reaccionarias funcionar dentro de la comunidad Bitcoin? (Trabajo de licenciatura). Universidad de San Andrés, Victoria. Recuperado de http://repositorio.udesa.edu.ar/jspui/bitstream/10908/11815/1/\%5bP\%5d\%5bW\%5d \%20T.\%20L.\%20Eco.\%20Ramos\%20Taboada\%2c\%20Federico.pdf.

Tapscott, D. y Tapscott, A. (2017). La revolución blockchain. Descubre cómo esta nueva tecnología transformará la economía global. Barcelona, España: Deusto. 